\title{
Ranibizumab: the evidence of its therapeutic value in neovascular age-related macular degeneration
}

\author{
Peter K. Kaiser \\ Cole Eye Institute, The Cleveland Clinic Foundation, Cleveland, Ohio, USA
}

\begin{abstract}
Introduction: Neovascular age-related macular degeneration (AMD) is the leading cause of severe, irreversible visual impairment in people over 60 years of age. Neovascular AMD is characterized by abnormal growth of blood vessels under the retina, specifically the macula. These vessels leak blood and fluids, damaging the retina and its photoreceptors, resulting in permanent loss of central vision. Vascular endothelial growth factor-A (VEGF-A) has been shown to play a critical role in the pathogenesis of neovascular AMD. In the US, ranibizumab, a VEGF-A blocker, is approved and indicated for the treatment of patients with neovascular AMD.
\end{abstract}

Aims: To review the clinical evidence for ranibizumab in the treatment of neovascular AMD.

Evidence review: Phase III clinical trial data have established ranibizumab as a safe and well-tolerated treatment for neovascular AMD. Monthly intravitreal injections of ranibizumab result in a statistically significantly greater proportion of patients losing $<15$ letters of visual acuity (VA) and statistically significant increases in the mean number of letters gained compared with controls. Anatomically, ranibizumab results in stabilization in the mean area of choroidal neovascularization (CNV) and statistically significant reductions in the mean area of leakage compared with controls. Although there is limited economic evidence available, ranibizumab therapy for neovascular AMD appears to deliver a significant degree of value gain in terms of quality of life when compared with other neovascular AMD interventions.

Place in therapy: Clinical evidence establishes ranibizumab as a first-line therapy option for virtually all treatable neovascular AMD patients. Updating neovascular AMD treatment guidelines to reflect the evidence base for ranibizumab as a preferred first-line therapy would be beneficial for physicians in making informed treatment choices and ultimately helping to ensure the best care for patients.

Core Evidence. 2008;2(4):273-294

Key words: ranibizumab, evidence, neovascular age-related macular degeneration

Core evidence place in therapy summary for ranibizumab in neovascular AMD

\begin{tabular}{|c|c|c|}
\hline Outcome measure & Evidence & Implications \\
\hline \multicolumn{3}{|l|}{ Patient-oriented evidence } \\
\hline Maintenance of visual acuity & Clear & $\begin{array}{l}95 \% \text { of patients maintain visual acuity; } 34-40 \% \text { of patients treated with ranibizumab experience a } \\
\text { clinically significant improvement of visual acuity (gaining } 15 \text { or more letters at } 12 \text { months) }\end{array}$ \\
\hline Improvement in vision & Clear & $\begin{array}{l}\text { Significantly more ranibizumab-treated patients have } 20 / 40 \text { (Snellen equivalent) vision after } 12 \text { and } 24 \\
\text { months of treatment than sham-treated patients; significantly fewer ranibizumab-treated patients have } \\
20 / 200 \text { vision after } 12 \text { and } 24 \text { months of treatment than sham-treated patients }\end{array}$ \\
\hline Quality of life & Limited & $\begin{array}{l}\text { Patients treated with ranibizumab demonstrate improvements in vision-specific quality of life } \\
\text { assessments using the National Eye Institute Visual Function Questionnaire-25 }\end{array}$ \\
\hline Safety and tolerability & Clear & $\begin{array}{l}\text { Serious adverse events }(<0.1 \%) \text { related to intravitreal injections, including those with ranibizumab, have } \\
\text { been associated with endophthalmitis and retinal detachments. Other serious ocular adverse events in } \\
<2 \% \text { of patients include intraocular inflammation and increased intraocular pressure }\end{array}$ \\
\hline \multicolumn{3}{|l|}{ Disease-oriented evidence } \\
\hline Decrease in classic CNV & Clear & Ranibizumab treatment is associated with arrested growth of CNV \\
\hline $\begin{array}{l}\text { Decrease in leakage from CNV and } \\
\text { staining of RPE }\end{array}$ & Clear & Ranibizumab treatment is associated with reduced leakage from CNV \\
\hline Need for repeated PDT therapy & Moderate & $\begin{array}{l}\text { Use of ranibizumab reduces the need for repeated PDT in the study eye when intravitreal ranibizumab } \\
\text { treatment is combined with verteporfin PDT }\end{array}$ \\
\hline $\begin{array}{l}\text { Decrease in OCT central retina } \\
\text { thickness }\end{array}$ & Moderate & $\begin{array}{l}\text { Mean and median central retina thickness, as measured by OCT, decreases beginning one day after the } \\
\text { first ranibizumab injection and over the next } 3 \text { months }\end{array}$ \\
\hline continued overleaf... & & \\
\hline
\end{tabular}


Ranibizumab | place in therapy review

\begin{tabular}{|lll|}
\hline $\begin{array}{l}\text {...table continued } \\
\text { Outcome measure }\end{array}$ & Evidence & Implications \\
\hline $\begin{array}{l}\text { Disease-oriented evidence } \\
\text { Reduction in the amount of } \\
\text { macular fluid }\end{array}$ & Moderate & $\begin{array}{l}\text { Intravitreal injections of ranibizumab rapidly reduce the amount of macular fluid; injections are stopped } \\
\text { if the macula is fluid-free, and when resumed, a single injection is usually sufficient to restore a } \\
\text { fluid-free macula }\end{array}$ \\
$\begin{array}{l}\text { Economic evidence } \\
\begin{array}{l}\text { Value gain associated with } \\
\text { ranibizumab }\end{array}\end{array}$ & $\begin{array}{l}\text { Ranibizumab for the treatment of neovascular AMD improves the average long-term vision with a value } \\
\text { gain of greater than 15\% }\end{array}$ \\
\hline AMD, age-related macular degeneration; CNV, choroidal neovascularization; OCT, optical coherence tomography; PDT, photodynamic therapy; RPE, retinal pigment epithelium. \\
\hline
\end{tabular}

\section{Scope, aims, and objectives}

Ranibizumab (Lucentis ${ }^{\circledR}$; Genentech, Inc.) is a humanized antigen-binding fragment (Fab) derived from a mouse monoclonal antivascular endothelial growth factor-A (VEGF-A) antibody (Rosenfeld et al. 2006a). Ranibizumab is indicated in the US for the treatment of patients with neovascular age-related macular degeneration (AMD) (Anon. 2007a).

This review summarizes the pathophysiology and natural history of neovascular AMD, describes the options currently available for the treatment of neovascular AMD, and examines the available evidence for ranibizumab in this indication. A detailed analysis of the large clinical evidence base for ranibizumab efficacy and safety in the treatment of neovascular AMD is discussed, including efficacy measures such as visual acuity (VA) and anatomic outcomes, as well as safety and tolerability data for ranibizumab in neovascular AMD patients. The appropriate place for ranibizumab in the treatment armamentarium for neovascular AMD is also discussed.

\section{Methods}

The English language medical literature in the following databases was searched between April 24 and July 10, 2007:

- PubMed, http://www.ncbi.nlm.nih.gov/entrez/query.fcgi, 1966 to date

- Clinical Trials.gov, http//clinicaltrials.gov

- Database of Abstracts of Reviews of Effects (DARE), National Health Service (NHS) Economic Evaluations Database (NHSEED), Health Technology Assessment (HTA), http://www.crd.york.ac.uk/crdweb/

- NHS HTA, http://www.ncchta.org

- National Guideline Clearinghouse, http://www.guideline.gov

- Cochrane Database of Systematic Reviews (CDSR), http://cochrane.org/index.htm. Entire site searched

- American Academy of Ophthalmology, http://www.aao.org/aao/
The search terms used were "ranibizumab OR Lucentis AND macular degeneration" and the cut-offs were from the beginning of the database to the date of the search. For the definition of levels of evidence, see Editorial Information on the inside back cover of journal. Papers from sources that were not peer reviewed or in which the search terms used were not the primary subject of the paper were excluded.

The proceedings of the following society meetings were searched for relevant abstracts using the terms "ranibizumab OR Lucentis AND macular degeneration":

- The Association for Research in Vision and Ophthalmology (ARVO) 2004-2007

- American Academy of Ophthalmology (AAO) 2004-2006

- The Retina Society 2004-2005

- Combined Meeting of Club Jules Gonin and the Retina Society 2006

- American Society of Retina Specialists 2006

Table 1 summarizes the level of evidence for the ranibizumab references located through literature searches.

\section{Disease overview}

\section{Epidemiology and risk factors}

AMD is a leading cause of severe, irreversible vision impairment in developed countries (AAO 2006). The prevalence of AMD increases with age; one in three people will be affected to some degree by the age of 75 (Stone 2006). The overall prevalence of neovascular AMD in the US population 40 years and older is estimated to be $1.47 \%$, with 1.75 million citizens having AMD (Friedman et al. 2004; AAO 2006). Based on the increasing number of older people in the population, it is estimated that the number of people with AMD may increase by $50 \%$ to 2.95 million by 2020 (Friedman et al. 2004).

There are multiple risk factors associated with AMD (Nowak 2006). Although age and family history are key risk factors, the most consistent factor associated with the development of AMD 
Table 1 | Evidence base included in the review

\begin{tabular}{|lcc|}
\hline Category & \multicolumn{2}{c|}{ Number of records } \\
\cline { 2 - 3 } & Full papers & Abstracts \\
\hline Initial search & 44 & 146 \\
$\quad$ records excluded & 14 & 106 \\
records included & 30 & 40 \\
Additional studies identified & 0 & 0 \\
Preclinical evidence & 2 & 0 \\
Level 1 clinical evidence & 4 & 0 \\
(systematic review, meta analysis) & & \\
Level 2 clinical evidence (RCT) & 4 & 8 \\
Level $\geq 3$ clinical evidence & 0 & 30 \\
$\quad$ trials other than RCT & 17 & 0 \\
$\quad$ Expert panels on AMD & 1 & 2 \\
Economic evidence & 2 & \\
\hline For definitions of levels of evidence, see Editorial Information on inside back cover or on \\
Core Evidence website (http://www.coremedicalpublishing.com). \\
AMD, age-related macular degeneration; RCT, randomized controlled trial. \\
\hline
\end{tabular}

is smoking (Klein et al. 2004). This modifiable risk factor doubles the risk of AMD, with an apparent dose-response relationship that increases with a greater number of pack years smoked (AAO 2006).

Several studies suggest that hypertension and cataract surgery also increase the risk of progression to late AMD, but the link is not conclusive (Klein et al. 2004). For other potential risk factors such as inflammatory disease, obesity, serum lipids, atherosclerotic vascular disease, and hyperopia, the findings are less consistent and the associations are often weaker (Klein et al. 2004). Diabetes has been hypothesized to increase the risk of AMD, but few epidemiologic studies have found such a risk (Klein et al. 2004). Similarly, exposure to ultraviolet (UV) light has been postulated as a cause of AMD, but no studies have demonstrated increased risk associated with UV-B exposure (Klein et al. 2004).

Family history is an important risk factor for AMD, and some individuals may have a genetic predisposition for developing AMD. In 2005, four articles described the increased risk of AMD associated with polymorphisms of complement factor $\mathrm{H}$ (HF1/CFH) (discussed in Moshfeghi \& Blumenkranz 2007). One variant in particular, $\mathrm{Y} 402 \mathrm{H}$, may account for approximately $50 \%$ of AMD cases (Hageman et al. 2005; Kuehn 2005). Recently, three additional genes that also potentially confer risk for AMDLOC387715 (ARMS2), PLEKHA1, and HTRA1-have been identified. There have been conflicting reports on the role of these three genes in AMD pathophysiology but there is evidence that suggests that the single nucleotide polymorphism (SNP) rs10490924 in the LOC387715 (ARMS2) gene and the rs11200638 SNP in HTRA1 contribute to the risk of development of AMD (reviewed in Ross et al. 2007). A more recent study suggests that the SNP in the LOC387715 (ARMS2) gene has direct effects on AMD risk presumably by affecting protein function, whereas the SNP in HTRA1 may be through an indirect pathway (Kanda et al. 2007). Analysis of the population- attributable risk of AMD estimates that HF1, LOC387715 (ARMS2), and cigarette smoking together explain $61 \%$ of the risk for AMD (Schmidt et al. 2006).

Several other genes have had at least one positive correlation with risk for AMD. Multiple variations in complement factor B (BF) and component 2 (C2) genes are associated with either increased risk for $A M D$ or providing protective effects against AMD, depending on the variant gene present (Gold et al. 2006); the $\mathrm{R} 32 \mathrm{Q}$ single nucleotide polymorphism of $\mathrm{BF}(\mathrm{H} 7)$ and a variant in intron 10 of $\mathrm{C} 2$ confer a significantly reduced risk of AMD (Gold et al. 2007). Recently, a role for complement C3 in the pathogenesis of AMD has also been described (Yates et al. 2007). It is likely that several different combinations of gene variants contribute to the risk for development of AMD. Continuing research will expand our knowledge of the genetics of AMD.

\section{Disease pathophysiology of neovascular AMD}

There are two clinical forms of AMD: dry AMD and neovascular AMD (Haddad et al. 2006). Dry AMD accounts for approximately $85 \%$ of total AMD cases (Haddad et al. 2006) and is characterized by off-white to yellow subretinal deposits called drusen and/or retinal pigment epithelium (RPE) irregularities. Some patients with dry AMD may have functional limitations including fluctuating vision, impaired reading, and limited vision at night or under conditions of reduced illumination, although they generally have good central vision (20/40 or better) (Fine et al. 2000). Dry AMD can progress to geographic atrophy and/or neovascular AMD. Geographic atrophy, sometimes described as the end stage of dry AMD, is characterized by localized areas of RPE and neural retina degeneration without subretinal neovascularization.

Neovascular AMD, also known as "wet AMD" or "exudative AMD," makes up about 15\% of total AMD cases (Haddad et al. 2006) and is characterized by choroidal neovascularization (CNV), usually involving the fovea (Nowak 2006). Development of neovascular AMD is usually accompanied by changes in VA that progress over weeks to months or longer (Brown et al. 2000). Visual changes can manifest as blurring, distortion, or the presence of dark spots in the central visual field (scotoma). The onset of neovascular AMD is heralded by the appearance of subretinal hemorrhage, intraretinal fluid, exudates, and lipid and/or subretinal fluid in the macula occurring secondary to CNV, resulting in loss of central vision (Brown et al. 2005). Untreated neovascular AMD generally causes more profound visual loss than dry AMD.

Many factors contribute to the disease process of neovascular AMD: smoking, genetics, RPE dysfunction, drusogenesis, local inflammation, and neovascularization (Nowak 2006). A complex interaction between these factors leads to the development and progression of neovascular AMD and vision loss (Fig. 1).

\section{Smoking}

Smoking contributes to the development and progression of AMD in a number of ways. Firstly, smoking reduces the concentration 


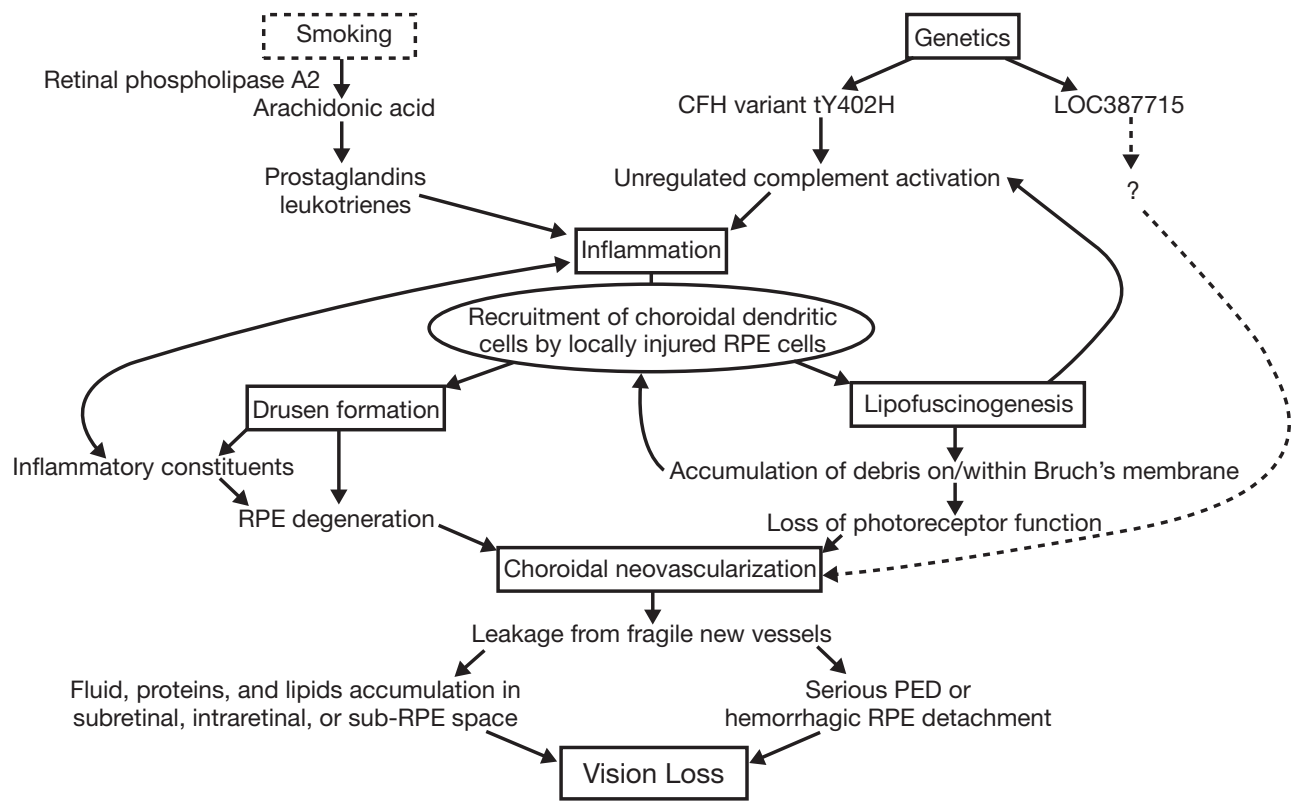

Fig. 1 | Factors and physiologic processes involved in the development and progression of neovascular AMD. AMD, age-related macular degeneration; PED, pigment epithelium derived; RPE, retinal pigment epithelium.

of macular pigment by as much as $50 \%$ in a dose-response relationship (Hammond et al. 1996). Macular pigments protect the macula by screening potentially harmful short-wavelength light and serving as an antioxidant; thus, any reduction in this pigment increases the risk for AMD (Hammond et al. 1996). Second, nicotine and cotinine in the plasma of smokers activates retinal phospholipase A2, causing the formation of arachidonic acid (Sastry \& Hemontolor 1998), a precursor to the inflammatory mediators prostaglandins and leukotrienes, which may contribute to macular degeneration (Sastry \& Hemontolor 1998). Third, smoking is associated with the local activation of macrophages that lead to an increase in photochemically damaged lipids and proteins along with apoptosis of RPE cells and photoreceptors (de Jong 2006). Thus, many molecular interactions associated with smoking can contribute to the development of AMD.

\section{Genetics}

Genetic factors contribute to the development and progression of neovascular AMD via inflammation (Moshfeghi \& Blumenkranz 2007), drusogenesis (DeWan et al. 2006; Moshfeghi \& Blumenkranz 2007), and neovascularization (DeWan et al. 2006). Specifically, some SNPs in CFH, which is a major inhibitor of the alternative complement pathway (Moshfeghi \& Blumenkranz 2007), are likely to render the protein products of this gene ineffective (de Jong 2006). The absence or low activity of CFH leads to unchecked alternative pathway activation that, over time, serves as an inflammatory stimulus leading to a permissive environment for drusen formation (Moshfeghi \& Blumenkranz
2007). Genetic variants in $B F$ and $C 2$ that are also involved in complement activation are associated with risk for development of AMD (Gold et al. 2006). As discussed above, the variations in the LOC387715 (ARMS2), PLEKHA1, and HTRA1 genes are also likely to contribute either directly or indirectly to the risk of developing AMD.

\section{RPE dysfunction}

Impairment of RPE cell function is an early and crucial event in the development of AMD. A driving force of RPE dysfunction is an age-dependent phagocytic and metabolic insufficiency of postmitotic RPE cells. These RPE cell deficiencies lead to progressive accumulation of lipofuscin granules composed of mostly lipids and proteins (Nowak 2006). Lipofuscin accumulation imposes an ever-increasing burden on RPE cell function. Increased lipofuscin in the RPE can lead to apoptosis, resulting in accumulation of debris on and within Bruch's membrane, and eventual loss of photoreceptor function. Accumulated lipofuscin absorbs light which damages the RPE and attracts macrophages, thereby evoking a local autoimmune response that leads to chronic inflammation (de Jong 2006). Products of lipofuscin photooxidation in RPE cells also serve as triggers for complement activation, further contributing to the chronic localized inflammation (Zhou et al. 2006).

\section{Drusogenesis}

Drusen are amorphous deposits that accumulate extracellularly in the area between the RPE and the inner collagenous zone of 
Bruch's membrane (Nowak 2006). Some drusen-associated constituents are locally produced by the RPE, choroid, and retina (Mullins et al. 2000). A possible association between the buildup of lipofuscin in RPE cells and drusen formation may exist, but such a relationship has not been firmly established (Zhou et al. 2006). Drusen and age-related changes that occur in the vicinity of Bruch's membrane may lead to dysfunction and/or degeneration of the RPE and retina by inducing ischemia and/or restricting the exchange of nutrients and waste products between the neural retina and choroid. Drusen themselves may have a detrimental effect on vision, particularly with respect to contrast sensitivity (Mullins et al. 2000). The presence of inflammatory constituents within drusen, such as complement activators, activation-specific complement fragments, and membrane attack complex, may contribute to local inflammation (Mullins et al. 2000; Russell et al. 2000; Anderson et al. 2002; Donoso et al. 2006).

\section{Local inflammation}

Drusen form, at least in part, as a result of localized chronic inflammation (Zhou et al. 2006; Moshfeghi \& Blumenkranz 2007). Injured RPE cells activate and recruit choroidal dendritic cells that may elicit an inflammatory or complement-mediated response (Hageman et al. 2001). Regardless of the initiating factor(s), local inflammation leads to up-regulation of inflammatory cytokines and infiltration of macrophages, resulting in localized damage and apoptosis of RPE cells, photoreceptors, and other cells within the retina (de Jong 2006).

\section{Neovascularization}

Angiogenesis, the formation and maturation of new blood vessels via sprouting or splitting from existing vessels, is characterized by a complex cascade of events (Kaiser 2006a). In order to stimulate angiogenesis, the molecular machinery must be unbalanced in favor of proangiogenic signaling (Nowak 2006). This results from an increase in proangiogenic factors such as VEGF or a decrease in antiangiogenic factors such as pigment epithelium-derived factor (PEDF).

VEGF-A is a primary driver of angiogenesis (Kaiser \& Do 2007). VEGF-A plays a critical role in the pathogenesis of neovascular AMD through its effects on angiogenesis and vascular permeability (Kaiser \& Do 2007). Under normal conditions, endothelial cells lining choroidal blood vessels of the retina are resistant to angiogenic stimuli (Nowak 2006). However, thickening of or damage to Bruch's membrane, presence of soft confluent drusen, RPE dysfunction, and pigment abnormalities create a permissive environment for the initiation of angiogenesis (AOA 2004). The resulting new vessels are fragile and do not mature properly, leaking blood and/or fluid with proteins and lipids into subretinal, intraretinal, or sub-RPE spaces (AOA 2004). This neovascularization and leakage results in the changes in vision associated with neovascular $A M D$, including loss of VA, particularly when the fovea is involved.

\section{Natural history of AMD}

The progression of AMD has been described and categorized by the Age-Related Eye Disease Study Research Group (AREDS), as presented in Table 2 (AREDS 1999, 2000, 2001). Patients with dry AMD are categorized as having early AMD (category 2) or intermediate AMD (category 3) while patients with neovascular AMD are considered to have advanced AMD (category 4).

\section{Table 2 | AMD categories and classifications [adapted from Age-Related Eye Disease Study Research Group} (AREDS) 2000]

\begin{tabular}{|c|c|}
\hline \multicolumn{2}{|l|}{ AMD category } \\
\hline Category 1 & No drusen or nonextensive small drusen only in both eyes \\
\hline Category 2 & $\begin{array}{l}\text { Extensive small drusen, nonextensive intermediate } \\
\text { drusen, or pigment abnormalities in at least one eye }\end{array}$ \\
\hline Category 3 & $\begin{array}{l}\text { Large drusen, extensive intermediate drusen, or } \\
\text { noncentral geographic atrophy in at least one eye }\end{array}$ \\
\hline Category 4 & $\begin{array}{l}\text { Advanced AMD (defined by the presence of at least } \\
\text { one of the following: geographic atrophy, retinal } \\
\text { pigment epithelial detachment in one eye, } \\
\text { choroidal neovascularization, or scars of confluent } \\
\text { photocoagulation) or visual acuity less than } \\
20 / 32 \text { attributable to lesions of nonadvanced AMD, } \\
\text { such as large drusen in the fovea, in only one eye }\end{array}$ \\
\hline Drusen size & $\begin{array}{l}\text { Based on largest drusen diameter as follows (relative to } \\
\text { the size of an average optic disc, considered by } \\
\text { convention to be } 1500 \mu \mathrm{m} \text { ) }\end{array}$ \\
\hline Small drusen & $<63 \mu \mathrm{m}(1 / 24$ disc diameter, standard circle $\mathrm{C}-0)$ \\
\hline $\begin{array}{l}\text { Intermediate } \\
\text { drusen }\end{array}$ & $\geq 63 \mu \mathrm{m}$ but $<125 \mu \mathrm{m}$ \\
\hline Large drusen & $\geq 125 \mu \mathrm{m}(1 / 12$ disc diameter, standard circle C-1) \\
\hline Drusen extent & $\begin{array}{l}\text { Variability in drusen size requires that total drusen area, } \\
\text { rather than drusen number, be considered }\end{array}$ \\
\hline Small drusen & $\begin{array}{l}\text { Considered extensive if the cumulative area within two } \\
\text { disc diameters of the center of the macula equal to at } \\
\text { least that of the AREDS standard circle C-1 (with diameter } \\
1 / 12 \text { that of the average disc) - this corresponds to } \\
\text { approximately } 15 \text { small drusen from stereo photographs } \\
\text { or } 5 \text { to } 10 \text { small drusen by ophthalmoscopic examination. }\end{array}$ \\
\hline $\begin{array}{l}\text { Intermediate } \\
\text { drusen }\end{array}$ & $\begin{array}{l}\text { Considered extensive if soft, indistinct drusen are } \\
\text { present and the total area occupied by the drusen is } \\
\text { equivalent to the area that would be occupied by } \\
20 \text { drusen each having a diameter of } 100 \mu \mathrm{m} \text {. If no soft } \\
\text { indistinct drusen are present, intermediate drusen are } \\
\text { considered to be extensive when they occupy an area } \\
\text { equivalent to at least } 1 / 5 \text { of a disc area (approximately } \\
65,100-\mu \mathrm{m} \text { diameter drusen) }\end{array}$ \\
\hline
\end{tabular}

In early AMD, patients generally have central VA similar to patients with a normal macula. There are little or no pigment epithelial abnormalities, small to intermediate drusen, and a $1.3 \%$ risk of progressing to advanced AMD within 5 years. Patients with intermediate AMD have extensive medium-sized, intermediate drusen, or one or more large drusen in one or both eyes. The chances of progression to advanced AMD are increased in these patients, with $18 \%$ progressing to advanced AMD at 5 years (AREDS 2001). The odds for the development of advanced AMD 
at 5 years are $26 \%$ in patients in whom drusen are present bilaterally, compared with $6.3 \%$ for patients with large drusen in only one eye. Patients with advanced AMD (AREDS category 4) have either neovascular AMD or geographic atrophy involving the fovea; therefore, VA is usually already affected in this category (AREDS 2001). Geographic atrophy is an advanced form of dry AMD in which there are one or more zones of sharply defined RPE and/or choriocapillaris atrophy. Geographic atrophy can lead to progressive loss of central vision if the fovea is involved (AAO 2006). Patients with advanced AMD or vision loss due to advanced dry AMD in one eye have a $43 \%$ chance of developing CNV or geographic atrophy in the fellow eye within 5 years (AREDS 2001).

In the Macular Photocoagulation Study, cases of classic and occult CNV were classified based on fluorescein angiography (FA) (MPS 1991; AAO 2006). Classic CNV is recognized as an area of bright, well-demarcated hyperfluorescence in the early phase of the angiogram, with progressive pooling of dye in the overlying subsensory retinal space during the late phases of the angiogram. Occult neovascularization consists of CNV that has indistinct or poorly demarcated boundaries on FA. Such CNV may be associated with an RPE detachment and/or late leakage of an undetermined source. Using these definitions, lesions associated with neovascular AMD are often categorized clinically and angiographically as occult, classic, or mixed occult and classic (minimally or predominantly classic) CNV (AAO 2006).

\section{New approaches for understanding and treating neovascular AMD}

VEGF-A is a primary driver of angiogenesis and plays a critical role in the pathogenesis of neovascular AMD through its effects on angiogenesis and vascular permeability (Kaiser \& Do 2007). VEGF-A expression is increased in pigment epithelial cells during the early stages of AMD (Kliffen et al. 1997), suggesting that VEGF-A may play a role in the initiation of neovascularization rather than being secondary to it (Kaiser 2006a). High concentrations of VEGF-A have been observed in excised choroidal neovascular membranes from AMD patients (Kvanta et al. 1996), and increased retinal and vitreous VEGF-A levels are found in both animals and humans with ischemic retinopathies induced by oxidative damage or hypoxia (Aiello et al. 1994; Pe'er et al. 1995). Thus, VEGF has become a frequent target for the development of new treatments for ocular neovascular diseases (Kaiser 2006a).

Two anti-VEGF therapies for AMD are FDA approved, with others in various stages of development. Currently available anti-VEGF agents include an aptamer (pegaptanib sodium), which targets the VEGF $_{165}$ isoform of VEGF-A, and the monoclonal antibody fragment ranibizumab, which targets all VEGF-A isoforms and cleavage products. Off-label bevacizumab is being used as a treatment for neovascular AMD as well. Bevacizumab is a monoclonal antibody specific for VEGF-A that is approved for the treatment of metastatic colorectal cancer and non-small cell lung cancer. Other anti-VEGF therapies in development include small interfering RNA (siRNA)-based therapies that silence specific genes via targeted degradation of mRNA, receptor tyrosine kinase inhibitors that target downstream activation of VEGF receptors, and VEGF Trap, which is a chimera of the ectodomains of VEGF receptor 1 and VEGF receptor 2 fused to an Fc portion of an antibody. VEGF Trap binds to VEGF-B and placental growth factor (PIGF) in addition to VEGF-A. The variable efficacy of these agents might reflect the specifics of how they target and block angiogenesis. In particular, whether or not an agent binds one or all VEGF-A isoforms appears to have a substantial impact on efficacy. Although the efficacy of these other antiangiogenic approaches has yet to be fully examined, further advances in treatment are likely (Kaiser 2006a). Additional targets are being explored for potential treatment of AMD, in particular the complement component proteins that have recently been identified as strong risk factors for the disease.

\section{Current therapy options}

The American Academy of Ophthalmology notes that even patients with neovascular AMD who receive appropriate treatment generally have a poor visual prognosis (AAO 2006). The treatment recommendation and follow-up plans for the treatment of AMD recently underwent limited revision by the American Academy of Ophthalmology Retina Panel (AAO 2006). The recommendations were given an explicit rating based on the importance to the care process and the strength of the evidence that supports the recommendation (AAO 2006).

The risks, benefits, and complications of the treatment should be discussed with the patient and informed consent obtained. Treatment options depend on the stage of the disease and diagnoses, as discussed below. Physicians are encouraged to promote healthy eating and to educate patients about the symptoms of AMD, thus prompting earlier presentation to ophthalmologists (Morris et al. 2007). Because of the considerable health benefits of smoking cessation, all patients who are currently smoking should be advised to stop regardless of AMD status (AAO 2006). Current smokers who modify their behavior may be able to reduce their risk of developing AMD (Tomany et al. 2004).

Observation is recommended, with no medical or surgical therapies, for patients with no clinical signs of AMD (AREDS category 1 ), early AMD (AREDS category 2), or advanced AMD with bilateral subfoveal geographic atrophy or disciform scars (AAO 2006). Since few patients in category 1 or 2 progress to advanced AMD, the effects of treatments within these patient populations cannot be evaluated (AREDS 2001). Recommended follow-up for these patients includes a return exam at 6-24 months or a prompt exam for new symptoms suggestive of CNV with no fundus photos or fluorescein angiography (FA) unless the patient is symptomatic (AAO 2006).

The AAO Retina Panel recommends antioxidant vitamin and mineral supplements for patients with intermediate AMD (AREDS category 3) or advanced AMD in one eye (AREDS category 4) (AAO 2006). Recommended follow-up for these patients includes the monitoring of monocular near vision via reading or Amsler 
grid, a return exam at 6-24 months if the patient is asymptomatic, with a prompt exam for new symptoms suggestive of CNV, fundus photography as appropriate, and FA if there is evidence of edema or other signs and symptoms of CNV.

For patients with CNV, a range of treatment options exists, depending on lesion type. The current treatment guidelines indicate that patients with subfoveal CNV can be treated with photodynamic therapy (PDT) with verteporfin, pegaptanib sodium, or ranibizumab (AAO 2006). Patients should be treated within 1 week after FA (AAO 2006). In order to describe the therapeutic value of ranibizumab for the treatment of neovascular AMD, the efficacy of other treatments currently used-PDT with verteporfin, pegaptanib sodium, and off-label bevacizumab-is presented for comparison.

\section{Ranibizumab}

Ranibizumab intravitreal injection $0.5 \mathrm{mg}$ is recommended for patients with subfoveal CNV. For this treatment, the AAO Retina Panel puts no limitations on treatment by the size or type of lesion. Recommended follow-up includes instructions to patients to report any symptoms of endophthalmitis without delay. Patients treated with ranibizumab should have follow-up exams, with re-treatments every 4 weeks as indicated, and undergo monitoring of monocular near vision (AAO 2006). The evidence for the use of ranibizumab is evaluated in the Clinical evidence section, below.

\section{PDT with verteporfin}

The AAO Retina Panel endorses the use of PDT with verteporfin as recommended in the Treatment of Age-Related Macular Degeneration with Photodynamic Therapy (TAP) and Verteporfin in Photodynamic Therapy (VIP) reports (TAP 1999; Bressler 2001; VIP 2001; Barbazetto et al. 2003) if the patient has new or recurrent $\mathrm{CNV}$ where the classic component is $>50 \%$ of the lesion and the entire lesion is $\leq 5400 \mu \mathrm{m}$ in greatest linear diameter (AAO 2006). Off-label use of PDT with verteporfin can be considered in patients with minimally classic CNV or occult with no classic CNV if vision is $<20 / 50$ or if CNV is $<4$ Macular Photocoagulation Study (MPS) disc areas in size when vision is $>20 / 50$ and there is evidence of recent disease progression, defined as a recent decrease in vision, an increase in size of the lesion, or hemorrhage associated with the lesion during the previous 3 months (AAO 2006). Follow-up recommendations include return exams approximately every 3 months until the patient is stable, with retreatments as necessary, FA or other imaging as indicated, and monitoring of monocular near vision (AAO 2006).

Two multicenter, double-masked, placebo-controlled, randomized clinical trials with 2 years of results supported approval of PDT with verteporfin as a treatment for neovascular AMD (Bressler 2001). In these trials, the primary outcome was the proportion of eyes with $<15$ letters of VA loss at 12 and 24 months (TAP 1999; Bressler 2001). Patients received either verteporfin (6 $\mathrm{mg} / \mathrm{m}^{2}$ body surface area) or placebo (5\% dextrose in water) followed by laser light, with the same treatment administered every 3 months for up to 24 months if FA showed evidence of fluorescein leakage (TAP 1999; Bressler 2001). At 12 months, $61 \%$ of verteporfin-treated patients and $46 \%$ of placebo-treated patients lost $<15$ letters of VA compared with baseline $(P<0.001)$. At this time point, subgroup analyses indicated that the VA benefit was clearly demonstrated in predominantly classic CNV lesions, especially when there was no occult CNV present (TAP 1999). At 24 months, $53 \%$ of verteporfin-treated patients lost $<15$ letters, compared with $38 \%$ of placebo-treated patients $(P<0.001)$. Subgroup analyses at 24 months indicated that patients with predominantly classic CNV lesions were more likely to exhibit a treatment benefit (Bressler 2001). Secondary treatment outcomes, including the proportion of eyes that had lost $<30$ letters compared with baseline, mean changes in VA, mean changes in contrast threshold, and the angiographic outcomes of the progression of CNV and the size of the lesion all favored PDT over placebo at the 12-month and 24-month intervals (TAP 1999; Bressler 2001). A recent report of the 5-year results from these trials has shown that vision outcomes remain relatively stable between month 24 and month 60, even though the treatment rate is low during this period (Kaiser 2006b).

\section{Pegaptanib sodium}

Pegaptanib sodium $0.3 \mathrm{mg}$ intravitreal injections can be used in patients with new or recurrent subfoveal CNV with predominantly classic lesions $\leq 12$ MPS disc areas in size. The AAO Retina Panel recommends that this treatment can be used in patients with minimally classic or occult CNV with no classic lesions where the entire lesion is $\leq 12$ disc areas in size, subretinal hemorrhage associated with CNV comprises $\leq 50 \%$ of the lesion, there is lipid present, and/or the patient has lost 15 or more letters of VA during the previous 12 weeks (AAO 2006). Recommended follow-up includes instructions to patients to report without delay any symptoms suggestive of endophthalmitis, including eye pain or increased discomfort, worsening eye redness, blurred or decreased vision, increased sensitivity to light, or an increased number of floaters. In addition, the patient should return for exams and re-treatment every 6 weeks as indicated.

Two pivotal clinical trials of pegaptanib sodium demonstrated the efficacy and safety of this pegylated aptamer in the treatment of neovascular AMD (Gragoudas et al. 2004). The primary efficacy outcome of the VEGF Inhibition Study in Ocular Neovascularization (VISION) trials was the proportion of patients who lost $<15$ letters of VA between baseline and week 54 . Patients received either intravitreal pegaptanib injections $(0.3,1.0$, or $3.0 \mathrm{mg}$ ) or sham injections every 6 weeks for 48 weeks. A significantly greater proportion of patients treated with pegaptanib than sham-treated patients lost $<15$ letters $(P<0.001$ for $0.3 \mathrm{mg}$ vs sham; $P<0.001$ for $1.0 \mathrm{mg}$ vs sham; and $P=0.03$ for $3.0 \mathrm{mg}$ vs sham). A total of $33 \%$ of pegaptanib-treated patients maintained or gained VA, compared with $23 \%$ of sham-treated patients $(P=0.003)$. A smaller percentage of patients in the pegaptanib groups than in the sham-injection group had a Snellen equivalent VA of $20 / 200$ or worse in the study eye at week 54 $(P<0.001$ for the comparison between all treatment groups and the sham-injection group). Angiographic examinations showed a 
slowing in the growth of the total area of a lesion, the size of CNV, and the severity of leakage in the groups receiving pegaptanib compared with the sham-injection group. Pegaptanib treatment appears to be safe; however, serious ocular adverse events (AEs) such as endophthalmitis (1.3\% of patients), traumatic lens injury $(0.7 \%$ of patients), and retinal detachment ( $0.6 \%$ of patients) have been reported. These studies demonstrate that pegaptanib is a safe and efficacious treatment for AMD, but its long-term safety has not been established (Gragoudas et al. 2004).

\section{Off-label bevacizumab}

Bevacizumab is approved for the treatment of colorectal and nonsmall cell lung cancer. Bevacizumab is being used off-label as a treatment for neovascular AMD and other neovascular diseases of the eye. The AAO Retina Panel notes that physicians should provide appropriate education to the patient and obtain informed consent with respect to the off-label status of the drug (AAO 2006). There is no limitation on the size of the lesion that can be treated with off-label bevacizumab, and treatment should be followed by return exams, with re-treatments every 4-8 weeks as indicated, with monitoring of vision (AAO 2006).

To date, no large, controlled, randomized clinical trials have been completed with off-label bevacizumab to demonstrate its safety or efficacy; however, there have been a number of small studies published. The results from one uncontrolled, open-label trial of systemic off-label bevacizumab therapy for the treatment of neovascular AMD have been reported (Michels et al. 2005). Systemic off-label bevacizumab was infused at the same dose and dosing interval currently approved for the treatment of metastatic colorectal cancer: $5 \mathrm{mg} / \mathrm{kg}$ with three initial infusions at 2-week intervals (Michels et al. 2005). In the study eye, significant increases in VA were evident within 1 week of treatment and continued through week 12. Median and mean central retinal thickness measurements decreased over 12 weeks. Angiography revealed a marked reduction or an absence of leakage from CNV. Similar results were seen in the fellow eye. Seven of nine patients experienced mildly elevated blood pressure (Michels et al. 2005). There are major disadvantages associated with systemic off-label bevacizumab therapy, the most significant of which is the possibility of life-threatening systemic AEs. These include increased risk of potentially fatal thromboembolic events and reduced wound healing after surgery, and possible detrimental effects to the normal eye (Michels et al. 2005).

Long-term studies of the efficacy and safety of systemic off-label bevacizumab for the treatment of AMD have not been performed.

There are several case studies and case series using intravitreal injection of off-label bevacizumab (Rosenfeld et al. 2005; Avery et al. 2006; Bashshur et al. 2006; Spaide et al. 2006). Dosing and follow-up varied. Improvements in VA from baseline (Avery et al. 2006; Bashshur et al. 2006; Spaide et al. 2006), decreased retinal thickness by optical coherence tomography (OCT) (Avery et al. 2006; Bashshur et al. 2006; Spaide et al. 2006), and a reduction in angiographic leakage in most patients (Rosenfeld et al. 2005;
Avery et al. 2006; Bashshur et al. 2006; Spaide et al. 2006) have been reported. Intravitreal injections of off-label bevacizumab were judged to be safe, with no significant ocular or systemic AEs observed; however, none of these retrospective studies systematically followed patients for safety issues (Rosenfeld et al. 2005; Avery et al. 2006; Bashshur et al. 2006; Spaide et al. 2006). Only one study excluded patients with uncontrolled hypertension or recent myocardial infarction or cerebral vascular accident (Avery et al. 2006). Long-term studies of the efficacy and safety of off-label bevacizumab intravitreal injection for the treatment of AMD have not been performed, but are being planned. The National Eye Institute's Comparison of Age-Related Macular Degeneration Treatments Trial (CATT) is being organized to directly evaluate the efficacy and safety of ranibizumab versus bevacizumab in the treatment of neovascular AMD. The results of the trial will most likely be available in several years, by which time new neovascular AMD therapies may have already changed the treatment landscape.

\section{Thermal laser photocoagulation surgery}

Another option that may be considered for patients with new or recurrent subfoveal CNV is thermal laser photocoagulation surgery, although it is rarely used (AAO 2006). The AAO Retina Panel states that it is useful for lesions that are $<2$ MPS disc areas and when VA is $20 / 125$ or worse, especially if PDT is contraindicated or not available (AAO 2006). Follow-up includes a return exam with FA approximately 2-4 weeks after treatment, and then at 4-6 weeks and thereafter depending on clinical and angiographic findings. Retreatment should be given as indicated, with continued monitoring of monocular near vision. For patients with new or recurrent extrafoveal classic CNV or juxtafoveal classic CNV, the only treatment option recommended by the AAO Retina Panel is thermal laser photocoagulation surgery (AAO 2006). This therapy may be considered for juxtapapillary CNV as well.

\section{New drugs in development}

The Pharmaceutical Research and Manufacturers of America (PhRMA) database lists 25 new medicines for the indication "agerelated macular degeneration" at various stages of development. These include anti-VEGF therapies, steroidal therapies, radiation therapy, and endogenous antiangiogenic factors (Nowak 2006).

Many of the drugs in development are anti-VEGF therapies, including the soluble receptor decoy VEGF Trap, 2 siRNA-based therapies [Sirna-027, which targets VEGF receptor $1 \mathrm{mRNA}$, and bevasirinib (Cand5), which targets VEGF-A mRNA], and several tyrosine kinase inhibitors [oral vatalanib (PTK787), subtenons AG013958, topical TG100801, and topical pazopanib]. Two drugs in development target genes involved in the production of VEGF rather than the activity of VEGF. Sirolimus (rapamycin) impacts upon the mammalian target of rapamycin (mTOR) and causes a decrease in VEGF production and a reduction in the response of vascular endothelial cells to stimulation by VEGF (Dejneka et al. 2004).

Steroidal therapies such as anecortave acetate and triamcinolone acetonide have antiangiogenic activity in addition to their 
antiinflammatory properties and may therefore inhibit CNV. A phase III trial for the treatment of CNV demonstrated that anecortave acetate was non-inferior to PDT, with the benefit outweighing the risk associated with the drug's mode of administration via posterior juxtascleral depot (PJD) (Slakter et al. 2006). The 2-year results of a retrospective analysis of triamcinolone acetonide added to PDT with verteporfin therapy stabilized best-corrected visual acuity (BCVA) and there was a reduction in the need for re-treatment (Ruiz-Moreno et al. 2007). Another therapy in development is beta-radiation therapy, which has a long history of use in ophthalmology (Kirwan et al. 2003). A clinical trial (CABERNET) of focal beta brachytherapy with strontium-90 delivered locally is expected to start patient recruitment soon to evaluate the safety and efficacy of this system in the treatment of subfoveal CNV associated with neovascular AMD. Several endogenous antiangiogenic factors such as angiostatin, endostatin, and PEDF are possible future therapeutics (Nowak 2006).

\section{Unmet needs in neovascular AMD}

The ultimate unmet need in neovascular AMD is prevention of the disease. To date, there is no treatment approved for preventing the development of neovascular AMD (SanGiovanni et al. 2007). However, incorporation of the AREDS vitamin and mineral supplement into the diet of patients with dry AMD may help to at least delay the onset of neovascular AMD (AREDS 2001). Recent advances in AMD genetics may provide the basis for the development of diagnostic tests to determine an individual's risk for AMD. Advances in discovering specific biomarkers for AMD may also provide a very early detection method to direct intervention before development of the disease.

Until the advent of anti-VEGF agents such as ranibizumab, there was a tremendous unmet medical need for effective treatments for neovascular AMD. The success of anti-VEGF agents for neovascular AMD has changed the standard of care and raised expectations for treatment beyond a slowing of vision loss; now, patients and physicians expect stabilization or improvement in vision. Notwithstanding the impressive efficacy of anti-VEGF agents, there are still unmet needs in neovascular AMD treatment. Even better efficacy is a clear unmet need, but more important is better modes of treatment administration. Currently, anti-VEGF agents are administered via intravitreal injection at least once per month. The injection procedure, while surprisingly well accepted by patients, is not an optimal method of drug delivery. Some patients and physicians find the injection frequency objectionable, and it may simply not be feasible in particular circumstances. An injectable or implantable longacting delivery device for anti-VEGF agents would be a significant step forward. Alternatively, the development of a simple eye drop formulation would also be highly desirable. These more convenient modes of administration could potentially reduce the amount of time AMD patients need to spend in physicians' offices, reducing strain on practices while making effective treatment less taxing to patients and their caregivers.

\section{Clinical evidence with ranibizumab in neovascular AMD}

Before exploring the body of clinical evidence for ranibizumab, it is important to understand the rationale for the drug and the design efforts that went into its creation. A rational drug design process was utilized with the following desirable qualities for an effective ocular antiangiogenic therapeutic: local deliverability into the eye, ability to penetrate through the retina to the sub-RPE space, high affinity for its target (all forms of VEGF-A), and safety and tolerability with minimal systemic exposure. In order to achieve these characteristics for a neovascular AMD treatment, a humanized anti-VEGF-A Fab was created. Ranibizumab was generated after several rounds of molecular modification that significantly increased binding affinity for its target, VEGF-A. Because of the location on VEGF-A to which ranibizumab binds, it has the ability to bind all VEGF-A forms with high affinity and inhibit their biologic activities (Genentech, Inc. unpublished data).

Preclinical evidence suggested that ranibizumab had potential to be an effective treatment for neovascular AMD. In-vivo pharmacokinetic studies in a monkey model indicated a favorable intraocular half-life (terminal half-life of approximately 3.6 days after intraocular administration of $0.5 \mathrm{mg}$ ranibizumab) and systemic half-life (terminal half-life of approximately 15.5 hours after intravenous administration of $1 \mathrm{mg}$ ranibizumab) (Gaudreault et al. 2005). A primate laser-induced CNV model of neovascular AMD was used to demonstrate that in pretreated eyes, intravitreal ranibizumab prevented CNV. In addition, eyes with established laser-induced CNV showed decreased leakage on FA and rapid resolution of CNV after intravitreal injections of ranibizumab (Krzystolik et al. 2002).

Six clinical studies investigating ranibizumab in the treatment of neovascular AMD have been published to date (Fig. 2).

- FVF2128g: a phase I/II, 30-week, multicenter, controlled, openlabel study of intravitreally administered ranibizumab $(0.3 \mathrm{mg}$ or $0.5 \mathrm{mg}$ ) versus usual care (UC) in patients with subfoveal predominantly or minimally classic AMD-related CNV (Heier et al. 2006a; Fig. 2a). To maximize the safety information obtained and provide an opportunity for those randomized to UC to later receive ranibizumab, patients were permitted to cross over to the alternative treatment after 3 months of randomized treatment (Heier et al. 2006a).

- FOCUS: a phase I/II, 2-year, multicenter, randomized, singlemasked, controlled study of injection of ranibizumab $0.5 \mathrm{mg}$ $(n=106)$ or sham $(n=56)$ in combination with verteporfin PDT versus verteporfin PDT alone (Heier et al. 2006b; Fig. 2b). This study was undertaken to investigate the safety and efficacy of intravitreal ranibizumab treatment combined with verteporfin PDT in patients with predominantly classic CNV secondary to AMD (Heier et al. 2006b).

- PrONTO: a phase II, 2-year, open-label, single-center, uncontrolled, investigator-sponsored study to evaluate an OCTguided variable-dosing regimen with intravitreal ranibizumab for 
Ranibizumab | place in therapy review

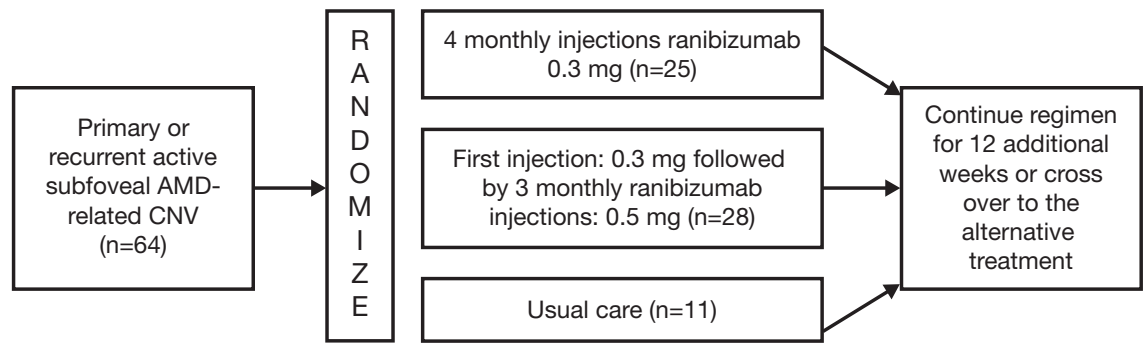

Fig. 2 | Study designs investigating ranibizumab in patients with neovascular AMD

Fig. 2a | Phase I/II, 30-week, multicenter, controlled, open-label study of intravitreally administered ranibizumab in patients with AMD (Trial FVF2128g; Heier et al. 2006a). AMD, age-related macular degeneration; CNV, choroidal neovascularization

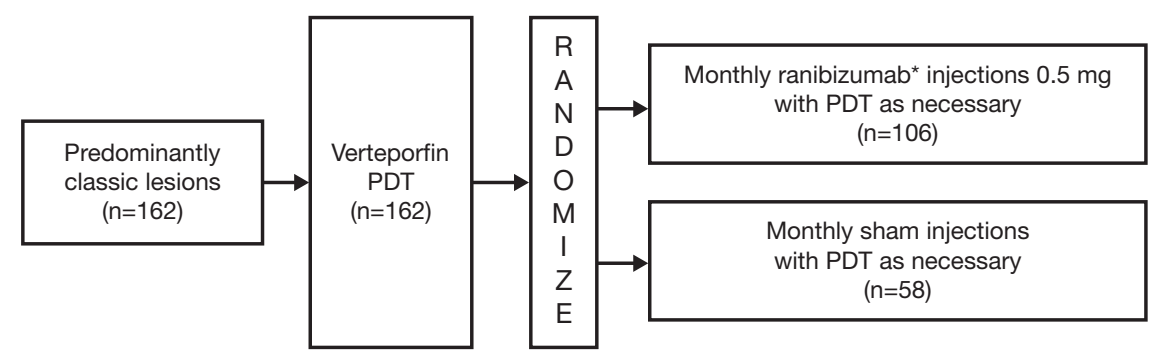

Fig. 2b | Phase I/II, 2-year, multicenter, randomized, single-masked, controlled study of $0.5 \mathrm{mg}$ ranibizumab in patients with AMD and PDT administered 7 days before (FOCUS trial; Heier et al. 2006b). *Lyophilized ranibizumab was used during the first 12 months of the trial. The formulation was replaced with the FDA-approved liquid formulation at varying time points during the second year of the trial. The trial protocol was amended on March 19, 2004 increasing the interval between PDT and subsequent ranibizumab/sham injection to a minimum of 28 days. AMD, age-related macular degeneration; PDT, verteporfin photodynamic therapy

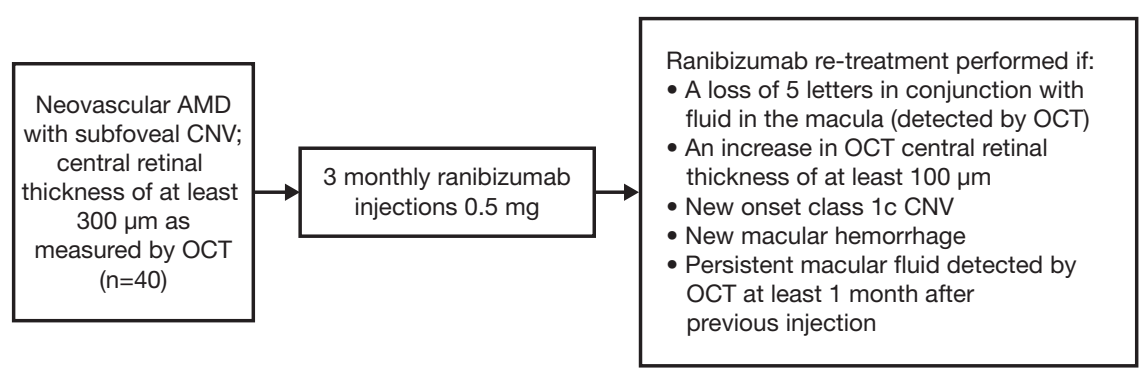

Fig. 2c | 2-year open-label, single-center, uncontrolled, investigator-sponsored clinical study of neovascular AMD patients with subfoveal CNV (PrONTO Trial; Fung et al. 2007b). AMD, age-related macular degeneration; CNV, choroidal neovascularization; OCT, optical coherence tomography 


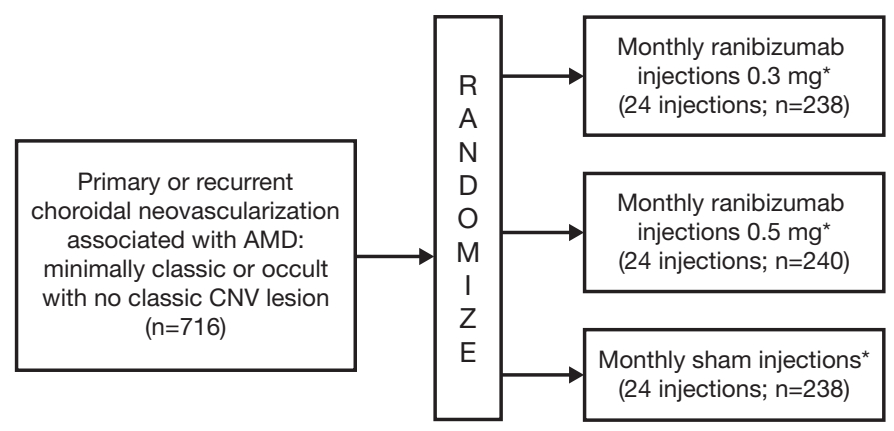

Fig. 2d | Multicenter, 2-year, double-blind, sham-controlled study of 24 intravitreal injections of ranibizumab or sham injections in patients with choroidal neovascularization AMD (MARINA Trial; Rosenfeld et al. 2006). *PDT allowed if the CNV became predominantly classic. Protocol amended to allow PDT for minimally classic or occult disease with no classic lesions that were no larger than four optic disc areas and accompanied by a loss of $\geq 20$ letters from baseline visual acuity. AMD, agerelated macular degeneration; CNV, choroidal neovascularization; PDT, verteporfin photodynamic therapy

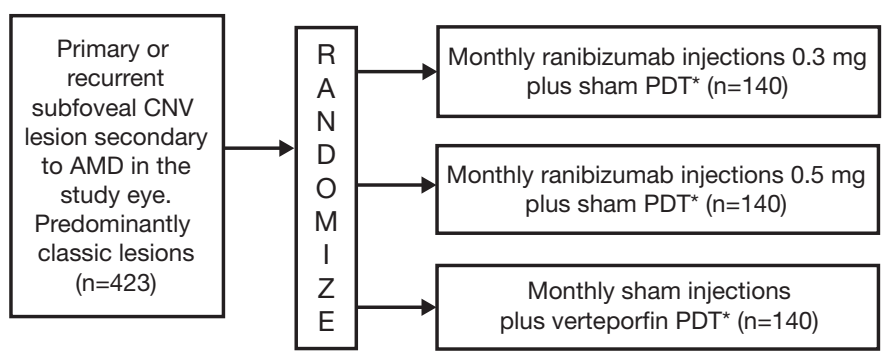

Fig. 2e | Phase III, multicenter, randomized, double-masked, active treatment controlled study of ranibizumab compared with PDT in subjects with predominantly classic subfoveal age-related macular degeneration (ANCHOR Trial; Brown et al. 2006a). *The necessity for repeat PDT treatment was determined based on angiographic evidence of vascular leakage. Thus, subjects randomized to the PDT group had the potential to have a verteporfin PDT treatment every 3 months. Subjects randomized to a ranibizumab group had the potential to receive a sham PDT treatment every 3 months. AMD, age-related macular degeneration; CNV, choroidal neovascularization; PDT, verteporfin photodynamic therapy

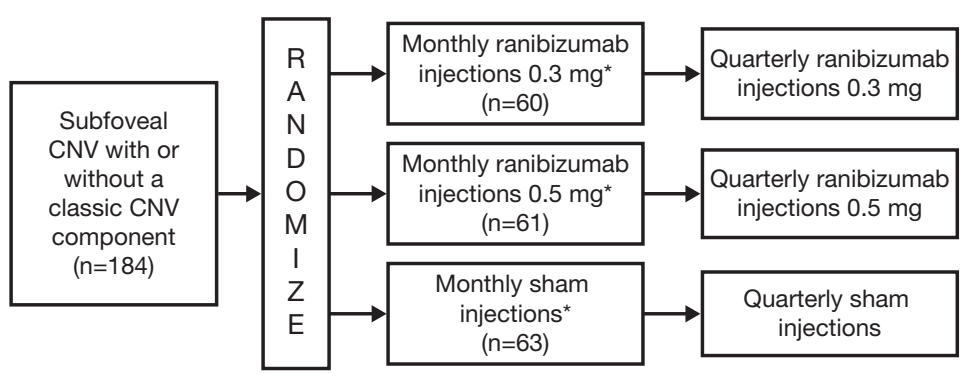

Fig. 2f | Phase Illb, randomized, double-masked, sham-controlled study of ranibizumab compared with sham injections in a fixed dosing regimen of three monthly doses followed by mandated quarterly dosing in subjects with primary or recurrent subfoveal CNV with or without a classic CNV component (PIER Trial; Anon. 2007a). *PDT allowed at investigator discretion: if the CNV became predominantly classic, or if loss of $\geq 20$ letters on two consecutive visits and small ( $\leq 4$ disc areas), minimally classic or occult with no classic lesions, with presumed recent disease progression, are observed. CNV, choroidal neovascularization; PDT, verteporfin photodynamic therapy 
the treatment of patients with neovascular AMD (Fung et al. 2007b; Fig. 2c). Patients with subfoveal CNV ( $n=40)$ and central retinal thickness of at least $300 \mu \mathrm{m}$ as measured by OCT received three consecutive monthly intravitreal injections of ranibizumab $0.5 \mathrm{mg}$. Thereafter, re-treatment with ranibizumab was performed based on specific re-treatment criteria (a loss of at least 5 letters in conjunction with increased fluid in the macula, increased central retinal thickness of at least $100 \mu \mathrm{m}$, new-onset classic CNV, new macular hemorrhage, or persistent macular fluid following an injection of ranibizumab at the prior study visit) (Fung et al. 2007b).

- MARINA: one of two pivotal phase III, multicenter, doubleblind 24-month studies, which compared monthly intravitreal injections of ranibizumab 0.3 or $0.5 \mathrm{mg}$ or sham injections $(n=716)$ in patients with minimally classic or occult CNV secondary to AMD (Rosenfeld et al. 2006a; Fig. 2d). Data from MARINA were further analyzed in a retrospective subgroup analysis to determine the effectiveness of ranibizumab across subgroups, compare the effectiveness of ranibizumab to sham injection within subgroups, and evaluate the relationship between selected baseline characteristics and VA outcomes (Boyer et al. 2007).

- ANCHOR: the second pivotal phase III, multicenter, randomized, double-masked 24-month clinical trial, which compared ranibizumab with the active control verteporfin PDT. ANCHOR patients were required to have predominantly classic subfoveal AMD $(n=423)$ and received monthly injections of ranibizumab 0.3 or $0.5 \mathrm{mg}$ combined with sham PDT or monthly sham injections plus active verteporfin plus PDT therapy every 3 months as necessary (Brown et al. 2006; Fig. 2e).

- PIER: a phase IIIb, randomized, double-masked, shamcontrolled study that compared ranibizumab 0.3 or $0.5 \mathrm{mg}$ with sham injections in patients with primary or recurrent subfoveal CNV with or without a classic CNV component $(n=184)$. The dosing regimen was three initial monthly doses followed by mandated quarterly dosing (Kaiser et al. 2006c; Anon. 2007a; Fig. 2f). A subgroup analysis was also performed to provide further insights into treatment strategies and patient monitoring (Brown et al. 2007a).

- PROTECT: there is limited evidence available in abstract form at the time of writing from this open-label phase II study performed in Europe. The safety and efficacy of same-day administration of PDT with verteporfin and concomitant intravitreal injection of ranibizumab $0.5 \mathrm{mg}$ is being evaluated in patients with predominantly classic or occult subfoveal CNV secondary to AMD ( $n=32$ ) (Schmidt-Erfurth et al. 2006; Wolf et al. 2006).

Select ongoing and planned phase IV studies with ranibizumab for the treatment of neovascular AMD are presented in Table 3.

\section{Visual acuity}

The effect of ranibizumab treatment on VA is summarized in Table 4. In two of the phase II trials (FVF2128g and PrONTO) and in the phase III trial PIER, change in VA was primarily measured as

Table 3 | Planned and ongoing phase IV studies with ranibizumab for the treatment of neovascular AMD

Study title Study description

Lucentis Utilizing Visudyne (LUV A phase IV trial comparing the use of Trial) Combination Therapy in the Treatment of Age-Related Macular Degeneration

Reduced Fluence PDT With Visudyne in Combination With Lucentis for Age-Related Macular Degeneration

Study Evaluating Genotypes Using Lucentis (SEAGUL) combination therapy with ITV ranibizumab and verteporfin PDT to ITV ranibizumab alone in patients with exudative AMD

Pilot study to evaluate the safety and efficacy of $50 \%$ reduced fluence PDT combination therapy with ranibizumab

To investigate whether the efficacy of ranibizumab treatment for exudative $\mathrm{AMD}$ is associated with VEGF and HTRA1 DNA polymorphisms
Outcome measures

Primary outcome measure

- Best-corrected ETDRS visual acuity at 3- and 12-month time points (gain or loss of $>15$ letters at 12 months)

Secondary outcome measures

- Number of ITV injections with ranibizumab needed by patients at 12 months

- OCT 3 macular thickness improvement (at baseline and 1, 2, 3, 6, and 12 months)

- Choroidal perfusion as assessed by ICG angiography at 1, 2, 3, 6, and 12 months

- Safety of combination therapy with verteporfin PDT and ITV ranibizumab

Primary outcome measure

- Mean change in BCVA of ETDRS letters from baseline at 12 months

Secondary outcome measures

- Time to first re-treatment after loading doses, average number of re-treatments over 12 months, central macular thickness on OCT, the number of recurrent $\mathrm{CNV}$, and the number of patients with persistent CNV after the mandatory loading doses

Primary outcome measure

- Determination of VEGF and HTRA1 genotypes associated with improvement in visual acuity (time frame: 4 months)

Secondary outcome measures

- Determination of VEGF and HTRA1 genotypes associated with change or no change in visual acuity (time frame: 12 months) 
Table 4 | Efficacy of ranibizumab on visual acuity in the treatment of neovascular AMD

\begin{tabular}{|c|c|c|c|c|c|c|c|}
\hline Study name & $\begin{array}{l}\text { Study } \\
\text { phase }\end{array}$ & Treatment and dose & $\begin{array}{l}\text { Proportion of } \\
\text { patients losing } \\
<15 \text { letters }\end{array}$ & $P$ value & $\begin{array}{l}\text { Change in visual } \\
\text { acuity (ETDRS } \\
\text { letters lost } \\
\text { or gained) }\end{array}$ & $P$ value & Reference \\
\hline \multirow[t]{3}{*}{ FVF2128g } & $1 / I I$ & Ranibizumab $0.3 \mathrm{mg}$ & N/A & & $+9.4 \pm 13.3$ & 0.0048 & Heier et al. 2006a \\
\hline & & Ranibizumab $0.5 \mathrm{mg}$ & & & $+9.1 \pm 17.2$ & 0.0024 & \\
\hline & & Usual care & & & $-5.1 \pm 9.6$ & & \\
\hline \multirow[t]{2}{*}{ FOCUS } & $1 / I$ & Ranibizumab $0.5 \mathrm{mg}+\mathrm{PDT}^{\mathrm{a}}$ & $90.5 \%$ & $<0.001$ & +4.9 & $<0.001$ & Heier et al. 2006b \\
\hline & & PDTa alone & $67.9 \%$ & & -8.2 & & \\
\hline \multirow[t]{2}{*}{ PrONTO } & ॥ & Ranibizumab $0.5 \mathrm{mg}$ & N/A & & +9.3 & $<0.001$ & Fung et al. 2007b \\
\hline & open-label & & & & & & \\
\hline \multirow[t]{3}{*}{ MARINA } & III & Ranibizumab $0.3 \mathrm{mg}$ & $94.5 \%$ & $<0.001$ & +6.5 & $<0.001$ & Rosenfeld et al. 2006 \\
\hline & & Ranibizumab $0.5 \mathrm{mg}$ & $94.6 \%$ & $<0.001$ & +7.2 & $<0.001$ & \\
\hline & & Sham injections & $62.2 \%$ & & -10.4 & & \\
\hline \multirow[t]{3}{*}{ ANCHOR } & III & Ranibizumab $0.3 \mathrm{mg}$ & $94.3 \%$ & $<0.001$ & +8.5 & $<0.001$ & Brown et al. 2006 \\
\hline & & Ranibizumab $0.5 \mathrm{mg}$ & $96.4 \%$ & $<0.001$ & +11.3 & $<0.001$ & \\
\hline & & PDT & $64.3 \%$ & & -9.5 & & \\
\hline
\end{tabular}

the mean number of letters gained or lost from baseline in response to ranibizumab treatment compared with control. In all other ranibizumab clinical trials, VA was primarily assessed as the proportion of ranibizumab-treated versus control patients who lost $<15$ letters from baseline.

\section{FVF2128g}

In this phase II trial comparing ranibizumab intravitreal injection to UC, VA was assessed at all study visits. At month 3 (after four monthly injections) VA increased $9.4 \pm 13.3$ and 9.1 \pm 17.2 letters for the ranibizumab 0.3 and $0.5 \mathrm{mg}$ dose groups, respectively. VA in the UC group decreased by a mean of 5.1 \pm 9.6 letters during the same period. The VA benefit of ranibizumab seen at 3 months persisted through 6 months, when the mean change from baseline VA increased to $11.6 \pm 14.0$ letters for $0.3 \mathrm{mg}$ ranibizumab and $11.8 \pm 14.1$ letters for $0.5 \mathrm{mg}$ ranibizumab. At 6 months, VA of patients in the UC group declined by a mean of $5.3 \pm 8.7$ letters (Heier et al. 2006a).

\section{PrONTO}

In the PrONTO study, at month 3 (1 month after the last scheduled monthly injection), mean VA improved by 10 letters $(P<0.001)$. By month 7 , mean VA increased by 9 letters compared with baseline (5 months after the last scheduled injection; $P<0.001$ ) (Rosenfeld et al. 2006b). At month 12, mean VA remained stable at a 9.3-letter improvement from baseline (Fung et al. 2007b). An analysis of the characteristics of patients who lost vision at year 1 of this study is available in abstract form (Fung et al. 2007a). It appears that VA loss was associated not with a failure to initially respond to ranibizumab therapy, but rather with anatomic changes within the macula (Fung et al. 2007a).

\section{FOCUS}

At 12 months, $90.5 \%$ of the ranibizumab plus PDT group versus $67.9 \%$ of patients in the PDT-only group lost $<15$ letters (Heier et al. 2006b). At 24 months, $87.5 \%$ of ranibizumab-treated patients lost $<15$ letters, compared with $75 \%$ of patients in the PDT-only group $(P=0.04)$. Also at 24 months, $24.8 \%$ of ranibizumab-treated patients gained $\geq 15$ letters of VA versus $7.1 \%$ in the control group $(P=0.006)$ (Lanzetta 2007). Mean VA improved in the ranibizumab-treated group by 4.6 letters over baseline, compared with a loss of 7.8 letters in the control group by month $24(P<0.0001)$ (Lanzetta 2007). The VA benefit described above was apparent as early as day 7 and was maintained throughout the study (Lanzetta 2007). In addition, $30.5 \%$ of ranibizumab-treated patients had a VA of $20 / 200$ or worse at month 24 , compared with $50 \%$ of the PDT group $(P=0.006)$ (Lanzetta 2007).

\section{MARINA}

More than $90 \%$ of patients in MARINA who were treated with ranibizumab lost $<15$ letters at 12 months: $94.5 \%$ of patients treated with $0.3 \mathrm{mg}$ and $94.6 \%$ of patients treated with $0.5 \mathrm{mg}$. By comparison, $62.2 \%$ of patients in the sham group lost $<15$ letters $(P<0.0001)$ (Rosenfeld et al. 2006a). VA was improved by $\geq 15$ letters for a significantly $(P<0.0001)$ greater number of ranibizumab-treated patients $(24.8 \%$ for $0.3 \mathrm{mg}$ and $33.8 \%$ for $0.5 \mathrm{mg}$ ) versus sham-treated patients (5.0\%). Mean increases in VA from baseline were 6.5 letters for the ranibizumab $0.3 \mathrm{mg}$ group and 7.2 letters for the ranibizumab $0.5 \mathrm{mg}$ group, whereas sham-injected patients had a mean decrease of 10.4 letters. This benefit in VA in ranibizumab-treated patients was maintained through 24 months (Rosenfeld et al. 2006a). 


\section{ANCHOR}

After 12 months of treatment in ANCHOR, 94.3\% of patients receiving ranibizumab $0.3 \mathrm{mg}$ and $96.4 \%$ of those receiving $0.5 \mathrm{mg}$ lost $<15$ letters, compared with $64.3 \%$ of PDT-treated patients $(P<0.0001)$ (Brown et al. 2006). As in MARINA, VA improved by $\geq 15$ letters in significantly more ranibizumab-treated patients $(35.7 \%$ for $0.3 \mathrm{mg}$ and $40.3 \%$ for $0.5 \mathrm{mg}$ ) than PDTtreated patients $(5.6 \% ; P<0.0001)$. At 12 months, mean change in VA increased by 8.5 letters in the ranibizumab $0.3 \mathrm{mg}$ group and by 11.3 letters in the $0.5 \mathrm{mg}$ group, but decreased by 9.5 letters in the sham group $(P<0.0001)$. An analysis of the time course of VA changes in the ANCHOR trial revealed that some patients who lost VA after 3 months of treatment with ranibizumab did have letter gains, sometimes $\geq 15$ letters, by month 12 (Heier et al. 2007). This indicates that even patients who did not show an early improvement in VA may still gain VA later in the course of monthly ranibizumab treatment (Heier et al. 2007).

\section{PIER}

The PIER trial resulted in an increase in VA following three monthly injections, at which time ranibizumab-treated patients had a mean gain of 4.7 letters (Anon. 2007a). However, the 3-month gains were not maintained with quarterly drug administration, and at month 12 mean VA returned to baseline levels (mean loss of 0.2 letters) (Anon. 2007a). Over the same period, sham-treated patients in PIER lost an average of 16.3 letters of VA. Therefore, despite the lack of overall VA gains in ranibizumab-treated patients, the difference in VA between ranibizumab- and sham-treated groups at month 12 was statistically significant $(P<0.01$; Genentech, Inc. unpublished data). Furthermore, the proportion of patients who lost $<15$ letters at month 12 was significantly greater in the ranibizumab group than in the control group $(P<0.01$; Genentech,
Inc. unpublished data). There was no statistically significant difference in the proportion of patients who gained $\geq 15$ letters at month 12 between the ranibizumab and sham groups ( $P=0.71$; Genentech, Inc. unpublished data).

\section{PROTECT}

In the PROTECT trial, verteporfin PDT and intravitreal ranibizumab $0.5 \mathrm{mg}$ were administered on the same day. The endpoints of the trial included the incidence of severe vision loss ( $\geq 30$ letters) and the effect of treatment on BCVA (SchmidtErfurth et al. 2006). No incidences of severe vision loss were observed, and the mean change in BCVA was +4.5 letters and +3.7 letters at 1 month and 3 months, respectively (SchmidtErfurth et al. 2006).

\section{Subgroup analyses}

In a retrospective subgroup analysis of MARINA, patients were divided based on baseline VA, age, and CNV lesion area. Within these subgroups, <15-letter loss from baseline, $\geq 15$-letter gain from baseline, and mean change in VA from baseline were determined (Boyer et al. 2007). Ranibizumab-treated patients exhibited a statistically significant improvement compared with sham-treated patients in all subgroups for all outcome measures. Sham-treated patients with higher baseline VA experienced a greater decline in VA over time than did sham-treated patients with lower baseline VA, suggesting a "floor effect" for patients with low baseline VA. For ranibizumab-treated patients, a higher baseline VA was reflected in a smaller mean improvement from baseline over time, suggesting a "ceiling effect" in those patients with a higher baseline VA. There was no significant correlation between increasing age, larger CNV lesion at baseline, or higher baseline VA and loss of $<15$ letters, gain of $\geq 15$ letters, or mean change in VA in either ranibizumab- or sham-treated patients.

\begin{tabular}{|c|c|c|c|c|c|c|}
\hline Study name & Treatment and dose & $\begin{array}{l}\text { Mean change in area of } \\
\text { CNV leakage (disc areas) } \\
\text { from baseline }\end{array}$ & $P$ value & $\begin{array}{l}\text { Mean change in CNV area } \\
\text { from baseline (disc areas) }\end{array}$ & $P$ value & Reference \\
\hline \multirow[t]{3}{*}{ FVF2128g } & Ranibizumab 0.3 mg & $-2.39 \pm 2.48$ & 0.0028 & $-0.14 \pm 1.48$ & 0.6230 & \multirow[t]{3}{*}{ Heier et al. 2006a } \\
\hline & Ranibizumab $0.5 \mathrm{mg}$ & $-1.57 \pm 2.53$ & 0.0699 & $-0.16 \pm 2.26$ & 0.3557 & \\
\hline & Usual care & $0.03 \pm 1.72$ & & $0.20 \pm 1.29$ & & \\
\hline \multirow[t]{2}{*}{ FOCUS } & Ranibizumab $0.5 \mathrm{mg}+\mathrm{PDT}^{\mathrm{a}}$ & $-2.3 \pm 2.4$ & $<0.001$ & $-0.1 \pm 1.5$ & $<0.001$ & \multirow[t]{2}{*}{ Heier et al. 2006b } \\
\hline & $\mathrm{PDT}^{\mathrm{a}}$ alone & $-0.6 \pm 2.8$ & & $1.3 \pm 2.2$ & & \\
\hline MARINA & $\begin{array}{l}\text { Ranibizumab } 0.5 \mathrm{mg} \text { vs } \\
\text { sham injection }\end{array}$ & $\begin{array}{l}\text { 3-disc area mean decrease } \\
\text { at month } 24\end{array}$ & $<0.01$ & $\begin{array}{l}\text { 2.6-disc area difference } \\
\text { at month } 24\end{array}$ & $<0.01$ & Rosenfeld et al. 2006 \\
\hline \multirow[t]{3}{*}{ ANCHOR } & Ranibizumab $0.3 \mathrm{mg}$ & $-1.80 \pm 1.72$ & $<0.001$ & $0.20 \pm 0.97$ & $<0.001$ & \multirow[t]{3}{*}{ Brown et al. 2006} \\
\hline & Ranibizumab $0.5 \mathrm{mg}$ & $-2.05 \pm 1.98$ & $<0.001$ & $0.22 \pm 1.25$ & $<0.001$ & \\
\hline & PDT & $0.32 \pm 3.09$ & & $1.63 \pm 2.37$ & & \\
\hline
\end{tabular}


In a PIER subgroup analysis, the effect of ranibizumab was consistent across age, sex, baseline VA, lesion size, CNV lesion type, and laser photocoagulation history (Brown et al. 2007a). However, the subgroup analysis revealed that patients with retinal thickness $<200 \mu \mathrm{m}$ following three monthly injections as determined by OCT maintained their initial VA improvements through 12 months, although they were not more likely to gain $\geq 15$ letters than controls (Brown et al. 2007a). Those patients who had dry lesions after the first 3 months of treatment as determined by FA also maintained initial improvements in VA but were more likely than controls to gain $\geq 15$ letters (Brown et al. 2007a). Thus, patients who had a retinal thickness $\geq 200 \mu \mathrm{m}$ or who had wet lesions after the first 3 months of treatment may have benefited more from continued monthly dosing (Brown et al. 2007a). The differences in responses of these patient subpopulations may explain why no gain in VA was observed at 12 months in the PIER trial.

\section{Anatomic outcomes}

Table 5 summarizes changes in mean area of CNV leakage and CNV area in response to intravitreal ranibizumab injection. Central retinal thickness was also assessed in some trials.

\section{FVF2128g/FOCUS}

In the phase II trials in which anatomic outcomes were reported, ranibizumab treatment resulted in decreases in total area of CNV and total area of leakage. In FVF2128g, the total area of CNV, total area of leakage, and mean total lesion area decreased with ranibizumab compared with UC (Heier et al. 2006a). In FOCUS, the total area of the CNV lesion, the total area of CNV, leakage from CNV, and the area of serous sensory retinal detachment (SSRD)/subretinal fluid were all significantly decreased in patients treated with ranibizumab plus PDT compared with those treated with PDT alone (Heier et al. 2006b).

\section{PrONTO}

In PrONTO, final central retinal thickness as measured by OCT was compared with baseline values (Fung et al. 2007b). At the end of 12 months of a variable ranibizumab dosing regimen, the mean and median central retinal thickness measurements decreased by $177.8 \mu \mathrm{m}(P<0.001)$ and $185.5 \mu \mathrm{m}(P<0.001)$, respectively. The change in retinal thickness as measured by OCT correlated with improvements in VA; a significant correlation was found with the Pearson analysis $(r=0.38, P=0.016)$, although the Spearman analysis was found to be borderline significant $(r=0.31, P=0.051)$.

\section{MARINA}

In MARINA, mean change from baseline in growth and leakage of CNV was significantly decreased in ranibizumab-treated patients versus sham-treated patients at both 12 and 24 months $(P<0.001)$ (Rosenfeld et al. 2006a). A retrospective analysis of data from patients in the MARINA trial also suggests that statistically significant benefits of ranibizumab over sham were observed for mean change from baseline in CNV area, total CNV area, and CNV leakage (Kaiser et al. 2007).
The angiographic results of the MARINA trial and OCT measurements of a subset of MARINA patients (those in which the study site's ophthalmic photographer was certified by the University of Wisconsin Fundus Photography Reading Center, thus reducing potential for variation by site) have been analyzed (Kaiser et al. 2007). The exploratory FA endpoint for this analysis included mean change from baseline in the area of SSRD at 12 and 24 months, and the exploratory endpoint for OCT was the mean change from baseline over time in center point thickness. Mean change in SSRD at 12 and 24 months was significantly decreased in ranibizumab-treated patients compared with the sham group $(P<0.0001)$. OCT measurements from a subset of patients ( $n=31$ ranibizumab-treated patients pooled; $n=15$ shamtreated patients) at month 12 demonstrated that the mean change from baseline center point thickness in the sham group was approximately zero. By contrast, in the pooled ranibizumab groups, there was an average $84 \mu \mathrm{m}$ decrease by day $7(P=0.010$ versus sham) with a continued decrease to $123 \mu \mathrm{m}$ by month 12 ( $P=0.021$ versus sham). The VA results in the patients analyzed in this subset were consistent with the entire cohort (Kaiser et al. 2007).

\section{ANCHOR}

At 12 months in the ANCHOR trial, ranibizumab-treated patients showed significant improvements in anatomic outcomes compared with verteporfin PDT-treated patients (Brown et al. 2006). The area occupied by classic CNV and area of leakage from CNV decreased in both ranibizumab-treated groups and increased in the verteporfin PDT group $(P<0.001$ for each comparison). The mean area occupied by CNV (classic and occult, if present) and mean lesion area increased in the verteporfin PDT group, while ranibizumab-treated patients had only small increases in these measures $(P<0.001$ for each comparison).

PIER

In PIER, leakage from CNV decreased in ranibizumab-treated patients and increased in sham-treated patients at month 12 compared with baseline (Genentech, Inc. unpublished data). The differences in area of leakage from CNV compared with shamtreated patients were statistically significant $(P<0.01$; Genentech, Inc. unpublished data).

\section{PROTECT}

Similar results were seen in the PROTECT study. Same-day ranibizumab and verteporfin PDT treatment was associated with reduced CNV leakage as assessed by FA. This change was accompanied by a statistically significant decrease in retinal thickness (Wolf et al. 2006).

\section{Number of treatments}

Ranibizumab treatment in the FOCUS, MARINA, and ANCHOR trials was once monthly injection for 24 months, and this regimen resulted in significant improvements in VA for ranibizumab-treated 
patients compared with controls (both sham and active). The results from the PIER trial in which ranibizumab was given monthly for 3 months and quarterly thereafter indicate that VA improvements with mandated quarterly administration were not as robust as with a monthly schedule (Kaiser et al. 2006c; Anon. 2007a). In PrONTO, the OCT-guided treatment regimen resulted in similar VA improvements as in MARINA and ANCHOR, but with fewer treatments (Fung et al. 2007b). Once a fluid-free macula was achieved, the mean injection-free interval was 4.5 months (Fung et al. 2007b). However, no trials have directly evaluated the administration of ranibizumab on a when-required basis compared with monthly dosing.

\section{Quality of life}

Data on patient-reported quality of life (QOL) and vision-related function (VRF) from the MARINA and ANCHOR trials are available in abstract form (Chang et al. 2006; Chang et al. 2007; Schwartz et al. 2007; Suner et al. 2007). Patient-reported vision-specific QOL was assessed using the National Eye Institute Function Questionnaire-25 (NEI VFQ-25). In MARINA, perception of driving function decreased less in ranibizumab-treated patients than in sham-treated patients over 24 months (Chang et al. 2007). Furthermore, overall self-reported vision-specific QOL improved in ranibizumab-treated patients, while sham-treated patients reported decreases (Chang et al. 2006). These improvements in vision-specific QOL resulted in decreased levels of vision-related dependency for ranibizumab compared with sham-treated patients (Chang et al. 2006). VRF also improved at 24 months following ranibizumab treatment compared to sham (Suner et al. 2007). Similar improvements in VRF and QOL were found through month 12 in ANCHOR (Schwartz et al. 2007).

\section{Safety and tolerability}

The safety and tolerability of ranibizumab intravitreal injection has been consistently demonstrated. In the FVF2128g trial, ranibizumab was generally well tolerated (Heier et al. 2006a). In FOCUS, there was no notable imbalance in the incidence of serious nonocular AEs between the treatment groups (ranibizumab + PDT versus PDT alone) (Heier et al. 2006b), although the ranibizumab plus PDT group had more vascular system AEs (8.6 versus $5.4 \%$; $P=0.54$ ) and fewer other AEs (9.5 versus $14.3 \%$; $P=0.43$ ) than the PDT group (Heier et al. 2006b). There were no ocular or systemic AEs attributable to the injection of ranibizumab in PrONTO (Fung et al. 2007b). In MARINA, the three treatment groups did not differ in their rates of nonocular AEs (Rosenfeld et al. 2006a). Serious ocular AEs were attributable either to the injection procedure (presumed endophthalmitis) or to ranibizumab (serious uveitis) (Rosenfeld et al. 2006a). Similar results were observed in ANCHOR with balanced ocular and non-ocular safety profiles for all treatment arms, although there was a trend toward increased rates of intraocular inflammation in ranibizumabtreated patients $(10.2 \%$ in the $0.3 \mathrm{mg}$ ranibizumab group, $15.0 \%$ in the $0.5 \mathrm{mg}$ ranibizumab group, and $2.8 \%$ in the PDT with verteporfin group) (Brown et al. 2006). Through month 12 of PIER, there were no reported serious ocular $A E s$ potentially related to intravitreal injection and no nonocular AEs that might be associated with anti-VEGF therapy as a class (Genentech, Inc. unpublished data).

\section{Ocular AEs}

There were no episodes of endophthalmitis, uveitis, retinal detachment, retinal tear, vitreous hemorrhage, lens damage, cataract progression, or prolonged intraocular pressure (IOP) elevation in PrONTO (Fung et al. 2007b). Ocular AEs were reported in the other trials, as discussed below.

\section{Intraocular inflammation}

In FVF2128g, the most common $\mathrm{AE}$ was reversible inflammation of $2+$ to $4+$ (inflammation was evaluated by grading flare and cells from 0 to $4+$ ), which occurred after $8 \%$ of injections; trace or greater inflammation occurred after $58 \%$ of injections (Heier et al. 2006a). The 2+ to 4+ inflammatory responses were most severe on the day after injection, and usually resolved without treatment by 14 days after injection (Heier et al. 2006a). In FOCUS, a total of 13 episodes of serious intraocular inflammation occurred in 12 patients $(11.4 \%)$ from the ranibizumab plus PDT group but none occurred in the PDT group $(P=0.009)$ (Heier et al. 2006b). This inflammation may have been due to the lyophilized ranibizumab preparation used in the first 12 months of this study. This hypothesis is supported by safety data from PROTECT, where the commercial preparation was used. Furthermore, this inflammation was not apparent in the MARINA slit-lamp examination of patients, who had only trace or 1+ across all groups (Rosenfeld et al. 2006a). In ANCHOR, the rates of intraocular inflammation were slightly higher in both ranibizumab groups compared with the verteporfin PDT group, and were consistent with MARINA (Brown et al. 2006). Overall, however, most patients had no observable inflammation, and the proportion of inflammation events graded $2+$ or higher among ranibizumab-treated patients was small (Brown et al. 2006).

\section{Injection-site hemorrhage and retinal tear}

The rates of retinal tear and vitreous hemorrhage were low in all ranibizumab-treated patients. In FVF2128g, one (1.9\%) patient had a retinal tear (Heier et al. 2006a). Vitreous hemorrhage occurred in $3.9-5.7 \%$ of ranibizumab-treated patients; the vitreous hemorrhage was severe in one patient, but it occurred in association with central retinal vein occlusion (CRVO) and resolved after 208 days (Heier et al. 2006a). The incidence of vitreous hemorrhage and retinal tear was also low in MARINA ( $0.4 \%$ in both ranibizumab groups for both types of event) (Rosenfeld et al. 2006a). One event of vitreous hemorrhage was reported in ANCHOR, in a patient treated with ranibizumab $0.3 \mathrm{mg}$, and there were no reports of retinal tear in this trial (Brown et al. 2006).

\section{Increases in intraocular pressure}

Increases in IOP were mostly mild and transient, resolving without treatment in FVF2128g (Heier et al. 2006a). In FOCUS, transient increased IOP AEs were reported in $16.2 \%$ of the ranibizumab plus PDT group versus $1.8 \%$ in the PDT-alone group $(P=0.007)$ 
(Heier et al. 2006b). The likelihood of experiencing a transient increase in IOP did not change significantly with repeated injections. Despite these increases in IOP, there was no notable increased incidence of cataract $(P>0.99)$ (Heier et al. 2006b).

Ranibizumab had no long-term effect on IOP as assessed by monthly preinjection measurements during the 2-year follow-up period in MARINA (Rosenfeld et al. 2006a). IOP was increased 1 hour after ranibizumab injections, but the absence of corresponding changes in preinjection measurements suggests that the postinjection increases were transient. Ranibizumab was not associated with an increased frequency of cataracts (Rosenfeld et al. 2006a).

In ANCHOR, transient changes in IOP after injections were common in the ranibizumab-treated patients (Brown et al. 2006). The proportion of patients with a postinjection IOP of $\geq 30 \mathrm{mmHg}$ was greater in both ranibizumab groups than in the verteporfin PDT group, but very few patients had measurements of $\geq 40 \mathrm{mmHg}$. The ranibizumab groups had an increased frequency of cataract formation $(10.9 \%$ in the $0.3 \mathrm{mg}$ group, $12.9 \%$ in the $0.5 \mathrm{mg}$ group, and $7.0 \%$ in the verteporfin group) and a small number of patients had changes in lens status reported during the first treatment year. With the exception of one severe cataract formation in the verteporfin PDT group, all AEs associated with cataracts were mild or moderate (Brown et al. 2006).

\section{Nonocular AEs}

\section{Vascular AEs}

Vascular AEs are a potential risk with anti-VEGF therapies, although this risk is minimal with intravitreal administration. In FOCUS, the rate of arterial thromboembolic events (ATEs) was similar for patients treated with ranibizumab plus PDT or PDT alone (Heier et al. 2006b). Treatment-emergent hypertension was reported at a higher rate in ranibizumab-treated patients, although all episodes in both treatments were described as mild, except for two patients in the ranibizumab plus PDT group whose hypertension was described as moderate. There were no imbalances between treatment groups in any type of bleeding $A E$.

In PrONTO, no systemic thromboembolic events occurred and no hypertension was newly diagnosed during the study (Fung et al. 2007b). After 1 year, there were mean decreases in systolic blood pressure $(8 \mathrm{mmHg})$ and diastolic blood pressure $(5 \mathrm{mmHg})$.

At 24 months in MARINA, the rate of AEs did not differ significantly among treatment groups (Rosenfeld et al. 2006a). Furthermore, the onset of AEs and the time of study treatment appeared to be unrelated. By 24 months, nonocular hemorrhage had occurred in more ranibizumab-treated patients than shaminjected patients, but none of the differences were significant (Rosenfeld et al. 2006a). Similarly, in ANCHOR, the differences in rates of AEs among treatment groups were not significant (Brown et al. 2006). No apparent relationship between the onset of those events and the time of treatment was observed. There was also no increase in mean systolic or diastolic blood pressure or in the rates of hypertension in the ranibizumab groups compared with control.

Recently, a planned interim safety analysis of an ongoing phase III study (SAILOR) indicated a higher incidence of stroke in patients treated with ranibizumab $0.5 \mathrm{mg}$ compared with those treated with $0.3 \mathrm{mg}$ (1.2 versus $0.3 \%$, respectively; $P=0.02$ ) (Anon. $2007 b$ ). Patients with a history of prior stroke appeared to be at a higher risk for a subsequent stroke. However, the incidence of stroke determined in the SAILOR interim analysis was less than the US average for strokes, which is $2.4 \%$ across all ages, and increases with age [age-adjusted incidence $2.2 \%$ in the 45-64 age group, $6.2 \%$ in the $65-74$ age group, and $12.5 \%$ in the 75 -and-over age group (Pleis \& Lethbridge-Çejku 2006)]. For the AEs of myocardial infarction or vascular death, the differences between the doses were not statistically significant. As this was an interim analysis, no firm conclusions can be drawn; a full analysis will be performed after the completion of the study, at which time more accurate determinations of stroke risk can be established.

\section{Development of antiranibizumab antibodies}

Because ranibizumab is a humanized Fab, it is expected to be less antigenic than full-length monoclonal antibodies, chimeric antibodies, or other large foreign molecules (Heier et al. 2006a). Systemic immunoreactivity to ranibizumab may reflect detection of preexisting antibodies to endogenous Fab fragments rather than specific antibodies to ranibizumab (Heier et al. 2006b). In FVF2128g, serum antibody assays indicated that no patient developed new antiranibizumab antibodies (Heier et al. 2006a). Systemic immunoreactivity to ranibizumab was present in some patients at baseline in FOCUS (Heier et al. 2006b), MARINA (Rosenfeld et al. 2006a), and ANCHOR (Brown et al. 2006). In FOCUS, the percentage of ranibizumab-treated patients testing positive for immunoreactivity did not exceed the percentage in the PDT-alone group, and review of the VA data and AEs revealed no clinically relevant effects in patients with positive immunoreactivity (Heier et al. 2006b). In MARINA, immunoreactivity rates increased similarly in all treatment groups during the first year. Although more ranibizumab-treated than sham-treated patients tested positive at month 24 , exploratory subgroup analyses revealed no clinically relevant differences between patients with or without immunoreactivity to ranibizumab (Rosenfeld et al. 2006a). Monitoring for immunoreactivity during the first treatment year of ANCHOR revealed an increase from baseline in the number of patients testing positive in the $0.5 \mathrm{mg}$ group but not the $0.3 \mathrm{mg}$ or verteporfin groups at 12 months. Proportionately more ranibizumab-treated patients who were immunoreactive at any point during ANCHOR had AEs associated with intraocular inflammation, although the small number of patients with immunoreactivity precludes drawing definitive conclusions (Brown et al. 2006). Immunoreactivity appeared to be unrelated to VA changes and nonocular AEs potentially related to immunoreactivity (Brown et al. 2006). Therefore, the clinical significance of the increased rate of systemic immunoreactivity with ranibizumab treatment is still unclear (Rosenfeld et al. 2006a). 


\section{Economic evidence}

In the US, ranibizumab is covered under Medicare Part B, although patients are responsible for a 20\% copayment after each injection (Steinbrook 2006). In many instances, supplemental insurance, Medicaid, or support programs for the poor or uninsured that are funded by the manufacturer or others cover most or all of the patients' out-of-pocket costs.

Ranibizumab treatment results in significant QOL benefits and has been shown to provide superior value to neovascular AMD patients (Brown et al. 2007c). For ophthalmologic interventions, in which length of life is generally unaffected, the value gain is equivalent to the improvement in QOL (Brown et al. 2007b,c). Preliminary data suggest the value gain for the treatment of occult/minimally classic CNV with ranibizumab is greater than 15\% (Brown et al. 2007c). In comparison, PDT with verteporfin treatment delivers a value gain of $8.1 \%$ for classic subfoveal CNV, pegaptanib sodium a $5.9 \%$ increase for subfoveal CNV, and laser photocoagulation a $4.4 \%$ increase for classic subfoveal CNV (Brown et al. 2007b,c).

Brown and colleagues posit that the value of a treatment has nothing to do with cost, although cost can be a legitimate secondary consideration (Brown \& Brown 2007). Although the cost of off-label bevacizumab is significantly lower than that of ranibizumab (Steinbrook 2006, Raftery et al. 2007), ranibizumab was specifically designed, tested, and approved for neovascular AMD. Its efficacy and safety have been demonstrated in several large, rigorous clinical trials, as discussed above. In retrospective and small prospective studies, off-label bevacizumab appears to have similar efficacy to ranibizumab, but a head-to-head trial of efficacy and safety has not yet been conducted, and rigorous clinical trial data are lacking in general for off-label bevacizumab in neovascular AMD (Raftery et al. 2007). Therefore, given the wealth of level 1 clinical data and documented QOL value gain of ranibizumab, it would seem that this treatment is currently the best option for neovascular AMD patients.

\section{Patient group/population}

Ranibizumab (Lucentis) is indicated for the treatment of patients with neovascular AMD (Anon. 2007a). This broad indication allows for treatment of all types of neovascular AMD-related lesions to be treated with ranibizumab. The two pivotal phase III trials and the additional supportive phase III trials for ranibizumab included patients with all three angiographic subtypes: predominantly classic, minimally classic, and occult. As with all clinical trials, there is some selection bias introduced by the inclusion/exclusion criteria. The exclusion criteria for these two trials restricted enrollment of patients with prior treatment of the study eye with verteporfin, external-beam radiation therapy, transpupillary thermotherapy (TTT), antiangiogenic drugs, or those with previous intravitreal drug delivery, vitrectomy, or submacular surgery. Other exclusion criteria were based on particular lesion characteristics including those patients with subretinal hemorrhage involving the center of the fovea, lesions with hemorrhage that was $\geq 50 \%$ of the total lesion area or $\geq 1$ disc area in size, subfoveal fibrosis or atrophy, or CNV in either eye due to other causes, such as ocular histoplasmosis, trauma, or pathologic myopia.

Analysis of subgroups of patients from MARINA indicated that the most important predictors of VA outcomes may be baseline VA score, CNV lesion size, and age (in that order), although ranibizumab treatment for 24 months was consistently superior to sham treatment in all subgroups examined (Boyer et al. 2007). A greater net benefit in AMD patients treated with ranibizumab compared with sham was seen in patients with higher baseline VA (Boyer et al. 2007), but overall, the subgroup analyses suggest that all patients with neovascular AMD can benefit from ranibizumab treatment.

Ranibizumab is contraindicated in patients with ocular or periocular infections and in patients with known hypersensitivity to ranibizumab or any of the excipients in ranibizumab (Anon. 2007a).

\section{Dosage, administration, and formulations}

Ranibizumab is an ophthalmic-grade solution for intravitreal injection only (Anon. 2007a). The recommended schedule and dose of ranibizumab for the treatment of neovascular AMD is via intravitreal injection once a month at a dose of $0.5 \mathrm{mg}$ (Anon. 2007a). The injection frequency can be reduced to one injection every 3 months after the first four injections if monthly injections are not feasible; however, this interval is less effective and is likely to lead to an approximate 5-letter loss of VA benefit over the following 9 months (Anon. 2007a). Ranibizumab should be administered under controlled aseptic conditions with adequate anesthesia and a broad-spectrum microbicide given prior to the injection (Anon. 2007a). Patients should be monitored for elevation in IOP and endophthalmitis following the injection (Anon. 2007a).

The use of OCT to guide the treatment regimen in the PrONTO trial resulted in similar VA increases as seen in MARINA and ANCHOR but with fewer treatments (Fung et al. 2007b). The outcomes suggest that OCT can be useful for guiding retreatment with intravitreal ranibizumab, and the use of an OCTguided dosing regimen may decrease the injection burden without necessarily sacrificing improvements in VA (Fung et al. 2007b). A decrease in the number of injections would also reduce the potential risk of injection-related complications, and an increase in the injection-free interval could reduce the burden of frequent follow-up evaluations (Fung et al. 2007b). No direct comparison of the efficacy of as-required injection versus monthly injection of ranibizumab has been made to date, and treatment recommendations should follow the approved regimen until additional data are available.

\section{Place in therapy}

Neovascular AMD is the leading cause of blindness in the elderly, and owing to the increasing age of the population, the number of persons with neovascular AMD may increase by $50 \%$ to 
2.95 million by 2020 (Friedman et al. 2004). There is no known method of preventing the development of advanced AMD (SanGiovanni et al. 2007) or CNV. However, it is clear that angiogenesis and vascular permeability are driven by VEGF-A (Kaiser 2006a; Kaiser \& Do 2007). Since VEGF-A is an important regulator of angiogenesis, it has become an important target for the treatment of ocular diseases, such as neovascular AMD, in which angiogenesis plays a role (Kaiser 2006a).

Several anti-VEGF-A therapies for AMD are available and others are currently in development (Kaiser 2006a). Current treatment guidelines discuss options for anti-VEGF-A therapy, including pegaptanib, ranibizumab, and off-label bevacizumab. Although bevacizumab is not approved by the FDA for use in neovascular AMD, the AAO Retina Panel does present the drug as an option as a therapy for neovascular AMD, with the caveat that the treating physician should provide appropriate informed consent with respect to the off-label status of bevacizumab (AAO 2006).

The superior efficacy of ranibizumab compared with verteporfin PDT has been demonstrated in the clinical trials. In the ANCHOR trial, ranibizumab was superior to verteporfin for treatment of predominantly classic neovascular AMD (Brown et al. 2006). Patients treated with ranibizumab showed statistically significant improvements in VA and a greater proportion lost $<15$ letters of VA compared with patients treated with PDT. Furthermore, ranibizumab resulted in significant improvements in anatomic characteristics such as the area occupied by CNV and the area of leakage.

In the FOCUS trial, the addition of ranibizumab treatment to PDT therapy was significantly more efficacious than PDT alone; there was no ranibizumab-alone arm in this trial, and thus the relative contribution of PDT to overall efficacy cannot be determined. It is clear that the addition of monthly ranibizumab to verteporfin PDT greatly reduced the need for additional verteporfin PDT treatments (Heier et al. 2006b). An ongoing clinical development program (SUMMIT) is designed to further explore the combination of PDT therapy plus ranibizumab and to provide insight into the efficacy, safety, treatment practice, and health economics of this combination therapy.

As demonstrated in the PrONTO trial, the use of OCT to guide the treatment regimen of ranibizumab resulted in similar VA improvements as in MARINA and ANCHOR but with fewer treatments, suggesting that the use of OCT to guide re-treatment with ranibizumab may decrease the injection burden (Fung et al. 2007b). A direct head-to-head trial will be necessary to unequivocally conclude that a variable dosing regimen using OCT is noninferior to a fixed monthly dosing regimen (Fung et al. 2007b).

The approval of ranibizumab for neovascular AMD has changed the definition of VA "maintenance". Prior to the demonstration that ranibizumab treatment could improve VA in patients with neovascular AMD, the loss of $<15$ letters of VA was considered maintenance. Ranibizumab has raised the treatment standard in that it has the potential to increase VA in many patients. Similarly, physician and patient expectations about anticipated outcomes following treatment for neovascular AMD have changed as well.
Ranibizumab also provides value when compared with many other neovascular AMD treatments. The value gain for the treatment of occult/minimally classic CNV with ranibizumab is greater than $15 \%$, compared with $4.4 \%$ for laser photocoagulation, $5.9 \%$ for pegaptanib sodium, and $8.1 \%$ for verteporfin PDT for subfoveal CNV (Brown et al. 2007c). Brown and colleagues also note that the value conferred by an intervention, rather than the associated cost effectiveness, should be the most important factor when deciding how to treat a patient (Brown et al. 2007b, Brown \& Brown 2007). Although ranibizumab has a significantly higher price than off-label bevacizumab (Raftery et al. 2007), the efficacy and safety of off-label bevacizumab have not been determined in randomized clinical trials, and off-label bevacizumab is not approved by the FDA for the treatment of neovascular AMD.

Clinical evidence supports the use of ranibizumab injection as a firstline therapy in neovascular AMD patients. Current treatment guidelines from the AAO Retinal Panel recommend ranibizumab for patients with subfoveal CNV (AAO 2006). The trial data indicate that all neovascular AMD patient groups are likely to benefit from ranibizumab therapy; therefore, there appears to be evidence to support the view that the current treatment guidelines should be updated to recommend ranibizumab as a preferred first-line therapy for all neovascular AMD patients.

\section{Acknowledgments}

Dr Kaiser declares that he has the following financial disclosure: research grant support, Genetech, Inc.

Medical writing support was provided by Louis De Tulleo at The Scienomics Group during the preparation of this paper. Responsibility for opinions, conclusions, and interpretation of data lies with the author.

\section{References}

Aiello LP, Avery RL, Arrigg PG, et al. Vascular endothelial growth factor in ocular fluid of patients with diabetic retinopathy and other retinal disorders. $\underline{\mathrm{NEngl} \mathrm{J}}$ Med. 1994;331:1480-1487.

AAO (American Academy of Ophthalmology Retina Panel). Age-related macular degeneration limited revision preferred practice pattern. 2006. Available at: http://www.aao.org/education/guidelines/ppp/amd_new.cfm (accessed May 31, 2007).

Anderson DH, Mullins RF, Hageman GS, Johnson LV. A role for local inflammation in the formation of drusen in the aging eye. Am J Ophthalmol. 2002;134:411-431.

Anon. Lucentis Prescribing Information. Available at: www.gene.com (accessed April 25, 2007a).

Anon. Lucentis/SAILOR dear healthcare provider letter. Available at: http://www.gene.com/gene/products/information/pdf/healthcare-providerletter.pdf (accessed April 25, 2007b).

AOA (American Optometric Association) Consensus Panel on Care of the Patient With Age-Related Macular Degeneration. Optometric clinical practice guideline: care of the patient with age-related macular degeneration. 2004. Available at: http://www.aoa.org/documents/CPG-6.pdf (accessed June 5, 2007).

AREDS (Age-Related Eye Disease Study Research Group). The Age-Related Eye Disease Study (AREDS): design implications. AREDS report no. 1. Control Clin Trials. 1999;20:573-600. 
AREDS (Age-Related Eye Disease Study Research Group). Risk factors associated with age-related macular degeneration: a case-control study in the Age-Related Eye Disease Study. Age-Related Eye Disease Study report number 3. Ophthalmology. 2000;107:2224-2232.

AREDS (Age-Related Eye Disease Study Research Group). A randomized, placebo-controlled, clinical trial of high-dose supplementation with vitamins $C$ and $\mathrm{E}$, beta carotene, and zinc for age-related macular degeneration and vision loss: AREDS report no. 8. Arch Ophthalmol. 2001;119:1417-1436.

Avery RL, Pieramici DJ, Rabena MD, Castellarin AA, Nasir MA, Giust MJ. Intravitreal bevacizumab (Avastin) for neovascular age-related macular degeneration. Ophthalmology. 2006;113:363-372.

Barbazetto I, Burdan A, Bressler NM, et al. Treatment of Age-Related Macular Degeneration with Photodynamic Therapy Study Group; Verteporfin in Photodynamic Therapy Study Group. Photodynamic therapy of subfoveal choroidal neovascularization with verteporfin: fluorescein angiographic guidelines for evaluation and treatment--TAP and VIP report No. 2. Arch Ophthalmol. 2003;121:1253-1268.

Bashshur ZF, Bazarbachi A, Schakal A, Haddad ZA, El Haibi CP, Noureddin BN. Intravitreal bevacizumab for the management of choroidal neovascularization in age-related macular degeneration. Am J Ophthalmol. 2006;142:1-9.

Boyer DS, Antoszyk AN, Awh CC, Bhisitkul RB, Shapiro H, Acharya NR; MARINA Study Group. Subgroup analysis of the MARINA study of ranibizumab in neovascular age-related macular degeneration. Ophthalmology. 2007;114:246-252.

Bressler NM; Treatment of Age-Related Macular Degeneration with Photodynamic Therapy (TAP) Study Group. Photodynamic therapy of subfoveal choroidal neovascularization in age-related macular degeneration with verteporfin: two-year results of 2 randomized clinical trials-TAP report 2. Arch Ophthalmol. 2001;119:198-207.

Brown GC, Sharma S, Brown MM, Kistler J. Utility values and age-related macular degeneration. Arch Ophthalmol. 2000;118:47-51.

Brown GC, Brown MM, Sharma S, et al. The burden of age-related macular degeneration: a value-based medicine analysis. Trans Am Ophthalmol Soc. 2005;103:173-184.

Brown DM, Kaiser PK, Michels M, et al; ANCHOR Study Group. Ranibizumab versus verteporfin for neovascular age-related macular degeneration. $\mathrm{N} \mathrm{Engl} \mathrm{J}$ Med. 2006;355:1432-1444.

Brown DM, Yue H, Shams N. Ranibizumab (Lucentis) in neovascular age-related macular degeneration (AMD): subgroup analysis of year 1 PIER efficacy data. Presented at: Association for Research in Vision and Ophthalmology Annual Meeting; May 6-10, 2007a; Fort Lauderdale, FL. Abstract 4540. Available at: http://www.arvo.org (accessed April 26, 2007).

Brown GC, Brown MM, Brown HC, Kindermann S, Sharma S. A value-based medicine comparison of interventions for subfoveal neovascular macular degeneration. Ophthalmology. 2007b;114:1170-1178.

Brown MM, Brown GC, Brown H. Value-based medicine and interventions for macular degeneration. Curr Opin Ophthalmol. 2007c;18:194-200.

Brown MM, Brown GC. Value-based medicine: the clear case for quality standards. Evidence Based Ophthalmol. 2007;6:181-182.

Campochiaro PA, Nguyen QD, Shah SM, et al. Adenoviral vector-delivered pigment epithelium-derived factor for neovascular age-related macular degeneration: results of a phase I clinical trial. Hum Gene Ther. 2006;17:167-176.

Chang TS, Fine JT, Bressler N. Self-reported vision-specific quality of life at 1 year in patients with neovascular age-related macular degeneration in 2 phase III randomized clinical trials of ranibizumab (Lucentis). Presented at: Association for Research in Vision and Ophthalmology Annual Meeting; April 30-May 4, 2006; Fort Lauderdale, FL. Abstract 5252. Available at: http://www.arvo.org (accessed April 26, 2007).

Chang TS, Bressler NM, Fine JT, Dolan CM, Ward J. Self-reported perception of driving function following ranibizumab treatment in patients with neovascular AMD. Presented at: Association for Research in Vision and Ophthalmology Annual Meeting; May 6-10, 2007; Fort Lauderdale, FL. Abstract 1830. Available at: http://www.arvo.org (accessed April 26, 2007).

Dejneka NS, Kuroki AM, Fosnot J, Tang W, Tolentino MJ, Bennett J. Systemic rapamycin inhibits retinal and choroidal neovascularization in mice. Mol Vis. 2004;10:964-972. de Jong PT. Age-related macular degeneration. $\underline{N \text { Engl J Med. }}$ 2006;355:1474-1485.

DeWan A, Liu M, Hartman S, et al. HTRA1 promoter polymorphism in wet agerelated macular degeneration. Science. 2006;314:989-992.

Donoso LA, Kim D, Frost A, Callahan A, Hageman G. The role of inflammation in the pathogenesis of age-related macular degeneration. Surv Ophthalmol. 2006;51:137-152.

Fine SL, Berger JW, Maguire MG, Ho AC. Age-related macular degeneration. $\underline{N}$ Engl J Med. 2000;342:483-492.

Friedman DS, O'Colmain BJ, Muñoz B, et al; Eye Diseases Prevalence Research Group. Prevalence of age-related macular degeneration in the United States. Arch Ophthalmol. 2004:122:564-572.

Fung AE, Lalwani GA, Michels S, et al. Characteristics of patients losing vision at year 1 of the PrONTO study. Presented at: Association for Research in Vision and Ophthalmology Annual Meeting; May 6-10, 2007a; Fort Lauderdale, FL. Abstract 4579. Available at: http://www.arvo.org (accessed April 26, 2007).

Fung AE, Lalwani GA, Rosenfeld PJ, et al. An optical coherence tomographyguided, variable dosing regimen with intravitreal ranibizumab (Lucentis) for neovascular age-related macular degeneration. Am J Ophthalmol. 2007b;143:566-583.

Gaudreault J, Fei D, Rusit J, Suboc P, Shiu V. Preclinical pharmacokinetics of Ranibizumab (rhuFabV2) after a single intravitreal administration. Invest Ophthalmol Vis Sci. 2005;46:726-733.

Giles MC, Wong TY. Correspondence: Ranibizumab for neovascular age-related macular degeneration. N Engl J Med. 2007;356:748-749.

Gragoudas ES, Adamis AP, Cunningham ET Jr, et al; VEGF Inhibition Study in Ocular Neovascularization Clinical Trial Group. Pegaptanib for neovascular agerelated macular degeneration. $N$ Engl J Med. 2004;351:2805-2816.

Gold B, Merriam JE, Zernant J, et al. Variation in factor B (BF) and complement component 2 (C2) genes is associated with age-related macular degeneration. Nat Genet. 2006;38:458-462.

Haddad S, Chen CA, Santangelo SL, Seddon JM. The genetics of age-related macular degeneration: a review of progress to date. Surv Ophthalmol. 2006;51:316-363.

Hageman GS, Luthert PJ, Victor Chong NH, Johnson LV, Anderson DH, Mullins RF. An integrated hypothesis that considers drusen as biomarkers of immunemediated processes at the RPE-Bruch's membrane interface in aging and agerelated macular degeneration. Prog Retin Eye Res. 2001;20:705-732.

Hageman GS, Anderson DH, Johnson LV, et al. A common haplotype in the complement regulatory gene factor $\mathrm{H}(\mathrm{HF} 1 / \mathrm{CFH})$ predisposes individuals to age-related macular degeneration. Proc Natl Acad Sci USA. 2005;102:7227-7232.

Hammond BR, Wooten BR, Snodderly DM. Cigarette smoking and retinal carotenoids: implications for age-related macular degeneration. Vision Res. 1996;36:3003-3009.

Heier JS, Antoszyk AN, Pavan PR, et al. Ranibizumab for treatment of neovascular age-related macular degeneration: a phase I/II multicenter, controlled, multidose study. Ophthalmology. 2006a;113:642.

Heier JS, Boyer DS, Ciulla TA et al. Ranibizumab combined with verteporfin photodynamic therapy in neovascular age-related macular degeneration: year 1 results of the FOCUS Study. Arch Ophthalmol. 2006b;124:1532-1542.

Heier JS, Chung C, Schneider S; ANCHOR Study Group. Time course of visual acuity changes with ranibizumab (Lucentis ${ }^{\mathrm{TM}}$ ) in the 2-year ANCHOR study of patients with neovascular age-related macular degeneration (AMD). Presented at: Association for Research in Vision and Ophthalmology Annual Meeting; May 6-10, 2007; Fort Lauderdale, FL. Abstract 2872. Available at http://www.arvo.org (accessed April 26, 2007).

Jakobsdottir J, Conley YP, Weeks DE, Mah TS, Ferrell RE, Gorin MB. Susceptibility genes for age-related maculopathy on chromosome 10q26. $\underline{\mathrm{Am} \mathrm{J}}$ Hum Genet. 2005;77:389-407.

Kaiser PK. Antivascular endothelial growth factor agents and their development: therapeutic implications in ocular diseases. Am J Ophthalmol. 2006a;142:660-668. 
Kaiser PK; Treatment of Age-Related Macular Degeneration with Photodynamic Therapy (TAP) Study Group. Verteporfin therapy of subfoveal choroidal neovascularization in age-related macular degeneration: 5-year results of two randomized clinical trials with an open-label extension: TAP report no. 8 . Graefes Arch Clin Exp Ophthalmol. 2006b;244:1132-1142.

Kaiser PK, Yue H, Shams N. Subgroup analyses of one-year results of the PIER study of ranibizumab in neovascular AMD. Presented at: American Academy of Ophthalmology Annual Meeting; November 11-14, 2006c; Las Vegas, NV. Abstract PA058. Available at: http://www.aao.org (accessed April 26, 2007).

Kaiser PK, Do DV. Ranibizumab for the treatment of neovascular AMD. Int $J$ Clin Pract. 2007;61:501-509.

Kaiser PK, Blodi BA, Shapiro H, Acharya NR; MARINA Study Group. Angiographic and optical coherence tomographic results of the MARINA study of ranibizumab in neovascular age-related macular degeneration. Ophthalmology. 2007;114:1868-1875.

Kanda A, Chen W, Othman M, et al. A variant of mitochondrial protein LOC387715/ARMS2, not HTRA1, is strongly associated with age-related macular degeneration. Proc Natl Acad Sci USA. 2007:104:16227-16232.

Kirwan JF, Constable PH, Murdoch IE, Khaw PT. Beta irradiation: new uses for an old treatment: a review. Eye. 2003;17:207-215.

Klein R, Klein BE, Linton KL. Prevalence of age-related maculopathy. The Beaver Dam Eye Study. Ophthalmology. 1992;99:933-943.

Klein R, Peto T, Bird A, Vannewkirk MR. The epidemiology of age-related macular degeneration. Am J Ophthalmol. 2004;137:486-495.

Kliffen M, Sharma HS, Mooy CM, Kerkvliet S, de Jong PT. Increased expression of angiogenic growth factors in age-related maculopathy. $\mathrm{Br} J$ Ophthalmol. 1997;81:154-162.

Krzystolik MG, Afshari MA, Adamis AP, et al. Prevention of experimental choroidal neovascularization with intravitreal anti-vascular endothelial growth factor antibody fragment. Arch Ophthalmol. 2002;120:338-346.

Kuehn BM. Gene discovery provides clues to cause of age-related macular degeneration. JAMA. 2005;293:1841-1845.

Kvanta A, Algvere PV, Berglin L, Seregard S. Subfoveal fibrovascular membranes in age-related macular degeneration express vascular endothelial growth factor. Invest Ophthalmol Vis Sci. 1996;37:1929-1934.

Lanzetta P; FOCUS Study Group. Combination intravitreal ranibizumab $0.5 \mathrm{mg}$ and verteporfin PDT versus verteporfin PDT alone in the FOCUS study of neovascular age-related macular degeneration (AMD). Presented at: Association for Research in Vision and Ophthalmology Annual Meeting; May 6-10, 2007; Fort Lauderdale, FL. Abstract 2869. Available at: http://www.arvo.org (accessed April 26, 2007).

Liew G, Mitchell P. Correspondence: Ranibizumab for neovascular age-related macular degeneration. N Engl J Med. 2007;356:747-748.

Michels S, Rosenfeld PJ, Puliafito CA, Marcus EN, Venkatraman AS. Systemic bevacizumab (Avastin) therapy for neovascular age-related macular degeneration twelve-week results of an uncontrolled open-label clinical study. Ophthalmology. 2005;112:1035-1047.

Mordenti J, Cuthbertson RA, Ferrara N, et al. Comparisons of the intraocular tissue distribution, pharmacokinetics, and safety of 125l-labeled full-length and Fab antibodies in rhesus monkeys following intravitreal administration. Toxicol Pathol. 1999;27:536-544.

Morris B, Imrie F, Armbrecht AM, Dhillon B. Age-related macular degeneration and recent developments: new hope for old eyes? Postgrad Med J. 2007;83:301-307.

Moshfeghi DM, Blumenkranz MS. Role of genetic factors and inflammation in age-related macular degeneration. Retina. 2007;27:269-275.

MPS (Macular Photocoagulation Study Group). Subfoveal neovascular lesions in age-related macular degeneration: guidelines for evaluation and treatment in the macular photocoagulation study. Arch Ophthalmol. 1991;109:1242-1257.

Mullins RF, Russell SR, Anderson DH, Hageman GS. Drusen associated with aging and age-related macular degeneration contain proteins common to extracellular deposits associated with atherosclerosis, elastosis, amyloidosis, and dense deposit disease. FASEB J. 2000;14:835-846.
Nowak JZ. Age-related macular degeneration (AMD): pathogenesis and therapy. Pharmacol Rep. 2006;58:353-363.

Pe'er J, Shweiki D, Itin A, Hemo I, Gnessin H, Keshet E. Hypoxia-induced expression of vascular endothelial growth factor by retinal cells is a common factor in neovascularizing ocular diseases. Lab Invest. 1995;72:638-645.

Pleis JR, Lethbridge-Çejku M. Summary health statistics for U.S. adults: national health interview survey, 2005. National Center for Health Statistics; 2006. Vital Health Stat series 10 number 232. Available at: http://www.cdc.gov (accessed July 10, 2007).

Raftery J, Clegg A, Jones J, Lotery A. Ranibizumab (Lucentis) versus bevacizumab (Avastin): modelling cost effectiveness. Br J Ophthalmol. 2007;91:1244-1246.

Rosenfeld PJ, Moshfeghi AA, Puliafito CA. Optical coherence tomography findings after an intravitreal injection of bevacizumab (Avastin) for neovascular age-related macular degeneration. Ophthalmic Surg Lasers Imaging. 2005;36:331-335.

Rosenfeld PJ, Brown DM, Heier JS, et al; MARINA Study Group. Ranibizumab for neovascular age-related macular degeneration. $\mathrm{N}$ Engl J Med. 2006a;355:1419-1431.

Rosenfeld PJ, Fung AE, Lalwani GA, et al. Visual acuity outcomes following a variable-dosing regimen for ranibizumab (Lucentis ${ }^{\mathrm{TM}}$ ) in neovascular AMD: the PrONTO study. Presented at: Association for Research in Vision and Ophthalmology Annual Meeting; April 30-May 4, 2006b; Fort Lauderdale, FL. Abstract 2958. Available at: http://www.arvo.org (accessed April 26, 2007).

Rosenfeld PJ, Brown DM, Schneider, S; MARINA and ANCHOR Study Groups. Ranibizumab for neovascular age-related macular degeneration. N Engl J Med. 2007;356:749-750.

Ross RJ, Verma V, Rosenberg KI, Chan CC, Tuo J. Genetic markers and biomarkers for age-related macular degeneration. Expert Rev Ophthalmol. 2007:2;443-457.

Ruiz-Moreno JM, Montero JA, Zarbin MA. Photodynamic therapy and highdose intravitreal triamcinolone to treat exudative age-related macular degeneration: 2-year outcome. Retina. 2007;27:458-461.

Russell SR, Mullins RF, Schneider BL, Hageman GS. Location, substructure, and composition of basal laminar drusen compared with drusen associated with aging and age-related macular degeneration. Am J Ophthalmol. 2000;129:205-214.

SanGiovanni JP, Chew EY, Clemons TE, et al; Age-Related Eye Disease Study Research Group. The relationship of dietary lipid intake and age-related macular degeneration in a case-control study: AREDS Report No. 20. Arch Ophthalmol. 2007;125:671-679.

Sastry BV, Hemontolor ME. Influence of nicotine and cotinine on retinal phospholipase A2 and its significance to macular function. $\mathrm{J}$ Ocul Pharmacol Ther. 1998;14:447-458.

Schmidt S, Hauser MA, Scott WK, et al. Cigarette smoking strongly modifies the association of LOC387715 and age-related macular degeneration. $\underline{\mathrm{Am} \mathrm{J}}$ Hum Genet. 2006;78:852-864.

Schmidt-Erfurth UM, Gabel P, Hohman T; PROTECT Study Group. Preliminary results from an open-label, multicenter, phase II study assessing the effects of same-day administration of ranibizumab (Lucentis ${ }^{\mathrm{TM}}$ ) and verteporfin PDT (PROTECT Study). Presented at: Association for Research in Vision and Ophthalmology Annual Meeting; April 30-May 4, 2006; Fort Lauderdale, FL. Abstract 2960. Available at: http://www.arvo.org (accessed April 26, 2007).

Schwartz SG, Bressler NM, Fine JT, et al. Patient-reported visual function over 24 months in predominantly classic neovascular AMD: results from ANCHOR, a phase III trial of ranibizumab and verteporfin PDT. Presented at: Association for Research in Vision and Ophthalmology Annual Meeting; May 6-10, 2007; Fort Lauderdale, FL. Abstract 1822. Available at: http://www.arvo.org (accessed April 26, 2007).

Shahar J, Avery RL, Heilweil G, et al. Electrophysiologic and retinal penetration studies following intravitreal injection of bevacizumab (Avastin). Retina. 2006;26:262-269.

Slakter JS, Bochow TW, D'Amico DJ, et al; Anecortave Acetate Clinical Study Group. Anecortave acetate (15 milligrams) versus photodynamic therapy for treatment of subfoveal neovascularization in age-related macular degeneration. Ophthalmology. 2006;113:3-13. 
Ranibizumab | place in therapy review

Spaide RF, Laud K, Fine HF, et al. Intravitreal bevacizumab treatment of choroidal neovascularization secondary to age-related macular degeneration. Retina. 2006;26:383-390.

Steinbrook R. The price of sight--ranibizumab, bevacizumab, and the treatment of macular degeneration. N Engl J Med. 2006;355:1409-1412.

Stone EM. A very effective treatment for neovascular macular degeneration. N Engl J Med. 2006;355:1493-1495.

Suner IJ, Bressler NM, Chang TS, Fine JT, Dolan CM, Ward J. Vision-related function after ranibizumab treatment by better- or worse-seeing eye: 24 month results from MARINA. Presented at: Association for Research in Vision and Ophthalmology Annual Meeting; May 6-10, 2007; Fort Lauderdale, FL. Abstract 1808. Available at: http://www.arvo.org (accessed April 26, 2007).

TAP (Treatment of Age-Related Macular Degeneration with Photodynamic Therapy) Study Group. Photodynamic therapy of subfoveal choroidal neovascularization in age-related macular degeneration with verteporfin: oneyear results of 2 randomized clinical trials--TAP report. Arch Ophthalmol. 1999;117:1329-1345.

Tomany SC, Wang JJ, Van Leeuwen R, et al. Risk factors for incident agerelated macular degeneration: pooled findings from 3 continents. Ophthalmology. 2004;111:1280-1287.

VIP (Verteporfin In Photodynamic Therapy) Study Group. Verteporfin therapy of subfoveal choroidal neovascularization in age-related macular degeneration: two-year results of a randomized clinical trial including lesions with occult with no classic choroidal neovascularization--verteporfin in photodynamic therapy report 2. Am J Ophthalmol. 2001;131:541-560.
Wells JA, Murthy R, Chibber R, et al. Levels of vascular endothelial growth factor are elevated in the vitreous of patients with subretinal neovascularisation. Br J Ophthalmol. 1996;80:363-366.

Wolf S, Gabel P, Hohman TC, et al; PROTECT Study Group. Fluorescein angiographic and OCT results from an open-label, multicenter, phase II study assessing the effects of same-day ranibizumab (Lucentis ${ }^{\mathrm{TM}}$ ) and verteporfin PDT (Visudyne ${ }^{\circledR}$ ). Presented at: Association for Research in Vision and Ophthalmology Annual Meeting; April 30-May 4, 2006; Fort Lauderdale, FL. Abstract 3542. Available at: http://www.arvo.org (accessed April 26, 2007).

Yang Z, Camp NJ, Sun H, et al. A variant of the HTRA1 gene increases susceptibility to age-related macular degeneration. Science. 2006;314:992-993. Yates JR, Sepp T, Matharu BK, et al; Genetic Factors in AMD Study Group. Complement C3 variant and the risk of age-related macular degeneration. $\underline{N}$ Engl J Med. 2007;357:553-561.

Zhou J, Jang YP, Kim SR, Sparrow JR. Complement activation by photooxidation products of $\mathrm{A} 2 \mathrm{E}$, a lipofuscin constituent of the retinal pigment epithelium. Proc Natl Acad Sci USA. 2006;103:16182-16187.

Correspondence: Peter K. Kaiser, MD, Cole Eye Institute, The Cleveland Clinic Foundation, 9500 Euclid Avenue, Desk i3, Cleveland, OH 44195, USA or at pkkaiser@aol.com 